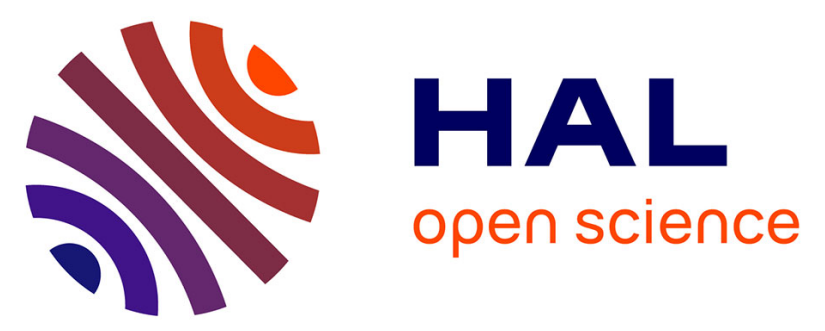

\title{
Leptin receptor gene in the European sea bass (Dicentrarchus labrax): cloning, phylogeny, tissue distribution and neuroanatomical organization
}

Sebastián Escobar, Ana Rocha, Alicia Felip, Manuel Carrillo, Silvia Zanuy, Olivier Kah, Arianna Servili

\section{To cite this version:}

Sebastián Escobar, Ana Rocha, Alicia Felip, Manuel Carrillo, Silvia Zanuy, et al.. Leptin receptor gene in the European sea bass (Dicentrarchus labrax): cloning, phylogeny, tissue distribution and neuroanatomical organization. General and Comparative Endocrinology, 2016, 229, pp.100-111. 10.1016/j.ygcen.2016.03.017 . hal-01290500

\section{HAL Id: hal-01290500 \\ https://hal-univ-rennes1.archives-ouvertes.fr/hal-01290500}

Submitted on 26 Apr 2016

HAL is a multi-disciplinary open access archive for the deposit and dissemination of scientific research documents, whether they are published or not. The documents may come from teaching and research institutions in France or abroad, or from public or private research centers.
L'archive ouverte pluridisciplinaire HAL, est destinée au dépôt et à la diffusion de documents scientifiques de niveau recherche, publiés ou non, émanant des établissements d'enseignement et de recherche français ou étrangers, des laboratoires publics ou privés. 
Leptin receptor gene in the European sea bass (Dicentrarchus labrax): cloning, phylogeny, tissue distribution and neuroanatomical organization.

Short title: Characterization of sea bass leptin receptor

Sebastián Escobar ${ }^{1,2,3, \S}$,Ana Rocha ${ }^{1, \S}$, Alicia Felip ${ }^{1}$, Manuel Carrillo ${ }^{1}$, Silvia Zanuy ${ }^{*}$, Olivier $\mathrm{Kah}^{2 *}$, Arianna Servilii ${ }^{2,4}$

${ }^{1}$ Department of Fish Physiology and Biotechnology, Instituto de Acuicultura de Torre la Sal (CSIC).Ribera de Cabanes s/n. 12595 Torre la Sal.Castellón. Spain.

${ }^{2}$ Team NEED, Research Institute for Health, Environment and Occupation, INSERM U1085, SFR Biosit, Université de Rennes 1, France.

${ }^{3}$ Present address: FAVET-INBIOGEN, Faculty of Veterinary Sciences, University of 18 Chile, Avda. Santa Rosa 11735, Santiago, Chile.

${ }^{4}$ Pressent address: IFREMER, CtBretagne, LEMAR, Unité PFOM ARN, F-29280 Plouzané, France

${ }^{\S}$ S. Escobar and A. Rocha contributed equally to this work

* Corresponding authors:

Olivier Kah, e mail:olivier.kah@univ-rennes1.fr and S. Zanuy, e-mail: s.zanuy@csic.es

Keywords: energy homeostasis, food intake, reproduction, central nervous system, teleost 


\section{Abstract}

In this study, we report the cloning of three transcripts for leptin receptor in the European sea bass, a marine teleost of economic interest. The two shortest variants, generated by different splice sites, encode all functional extracellular and intracellular domains but missed the transmembrane domain. The resulting proteins are therefore potential soluble binding proteins for leptin. The longest transcript (3605 bp), termed sblepr, includes all the essential domains for binding and transduction of the signal. Thus, it is proposed as the ortholog for the human $L E P R$ gene, the main responsible for leptin signalling. Phylogenetic analysis shows the sblepr clustered within the teleost leptin receptor group in $100 \%$ of the bootstrap replicates. The neuroanatomical localization of sblepr expressing cells has been assessed by in situ hybridization in brains of sea bass of both sexes during their first sexual maturation. At histological level, the distribution pattern of sblepr expressing cells in the brain shows no clear differences regarding sex or reproductive season. Transcripts of the sblepr have a widespread distribution throughout the forebrain and midbrain until the caudal portion of the hypothalamus. A high hybridization signal is detected in the telencephalon, preoptic area, medial basal and caudal hypothalamus and in the pituitary gland. In a more caudal region, sblepr expressing cells are identified in the longitudinal torus. The expression pattern observed for sblepr suggests that in sea bass, leptin is very likely to be involved in the control of food intake, energy reserves and reproduction. 


\section{Introduction}

Leptin is a member of the class-I helical cytokine which was firstly discovered in mouse as the anti-obese hormone. In mammals, is mainly synthesized by the adipose tissue and its signaling pathways act on the brain to adjust the amount of body fat deposits according to the available energy (Wang et al., 2004). Nowadays, several evidences reported in literature on mammals confirm that besides the major role of leptin in energy homeostasis and metabolism this hormone exerts a plethora of different functions, such as reproduction, immune and stress responses, bone formation and angiogenesis (Allison and Myers, 2014; Park and Ahima, 2014)

Over the last 10 years, there has been an increasing interest in the molecular characterization and function of leptin in non-mammalian vertebrates, and in particular in fish. In this later group, due to genome duplication events, up to four leptin genes have been identified in some species such as Atlantic salmon (Angotzi et al., 2013). However only two genes have been described in more evolved species such as tilapia and medaka (Shpilman et al., 2014; Gorissen et al., 2009). Fish sequences generally show low amino acid identity with human leptin form (13-25\%) (Gorissen and Flik, 2014). The other common feature among fish leptins is that the distinct isoforms present in the same species usually display differential tissue expression patterns suggesting a potential diversification of physiological functions (Angotzi et al., 2013; Gorissen et al., 2009; Kurokawa and Murashita, 2009). Although the major research focus so far has been the role of leptin in feeding and energy metabolism, research into the contribution of the leptin system in sexual maturation is gaining strength. Leptin stimulates release of luteinizing hormone (Lh) and somatolactin in European sea bass and both gonadotropins in rainbow trout (Peyon et al., 2001, 2003; Weil et al., 2003) and the 
main sexual steroids directly affect the hepatic expression of lepal and lepa2 in Atlantic salmon (Trombley et al., 2015). An increase in lep genes expression has also been associated with sexual maturation in Atlantic salmon male (Trombley et al., 2014) and Arctic charr (Frøiland et al., 2010). Nevertheless a direct involvement of leptin in this process has still to be demonstrated. The physiological actions of this cytokine are mediated by the leptin receptor (Lepr), a membrane spanning receptor of the class-I cytokine receptor family (Tartaglia, 1997). In mammals, six splice variants of the Lepr have been characterized of which only the long form encodes all intracellular domain protein motifs necessary for signaling. In the central nervous system of mammals it is the long form the responsible for leptin signal transduction. In fact, the long form of Lepr is mainly expressed in the hypothalamic arcuate nucleus, being particularly linked to two different types of neurons. Leptin directly acts on the orexigenic neuropeptide $\mathrm{Y}$ and agouti-related peptide neurons (by inhibition of protein expression) and, on the other hand, it also binds on the anorexigenic proopiomelanocortin and the cocaine and amphetamine cells (stimulating the transcription) (Broberger et al., 1998; Elias et al., 1998). Beside the long form of the leptin receptor, five shorter isoforms generated by alternative splicing events, have been characterized in mammals, each one showing distinct signaling capacities due to different truncations of the intracellular segment (Lee et al., 1996; Bjørbaek et al., 1997; Wang et al., 1996). Truncated receptor isoforms show much wider tissue distribution compared to the long form, mostly localized into the central nervous system (CNS).

While fish express two or more leptin genes, only one orthologous of the Lepr gene has been identified in fish genomes likely binding all the leptin isoforms (Gorissen et al., 2009; Prokop et al., 2012). Several lepr splice variants have been isolated in different fish species but, like the case of mammals, only the long form seems to contain all the 
protein domains required for intracellular signal transcription (ligand binding domain, transmembrane domain, JAK and STAT docking sites) (Gong et al., 2013; Rønnestad et al., 2010). Most studies on fish focused so far on the molecular characterization, phylogenetic analysis and tissue expression pattern of lepr, nevertheless little is known about the physiology and functions of this receptor. Notably, the detailed neuroanatomical localization of lepr expressing cells in distinct brain regions is still lacking in fish, with the exception of the pioneer work on embryos and adults of zebrafish (Liu et al., 2010).

In the current study we report the cloning and the exhaustive characterization of the lepr in the European sea bass (Dicentrarchus labrax). This teleost is a marine perciform of great economic interest that shows a clear interaction between growth, feeding and reproduction (Carrillo et al. 2015). But much remains to be done to understand the possible neuroendocrine role of leptin in this species. With the aim of contributing to this understanding, in the present work we isolated sea bass lepr gene and two alternatively-spliced isoforms and studied lepr tissue distribution pattern as well as its neuroanatomical localization.

\section{Material and methods}

\section{Animals and tissue collection}

Male and female European sea bass (Dicentrarchus labrax) of 2 and 3 years of age, respectively, were raised under natural photoperiod and temperature conditions at the facilities of the Instituto de Acuicultura de Torre de la Sal (Spain) (40 NL). They were sampled at two different periods during their first sexual maturation: in September (non breading; GSI: $0.08 \pm 0.01$ and $0.61 \pm 0.15$ males and females, respectively) and February (breeding; GSI: 4,01 \pm 0.19 and $5.46 \pm 0.93$ males and females, respectively). 
The first sampling was performed during the onset of spermatogenesis in males (stage II) and previtellogenesis in females, and the second one at spermiation in males (stage V) and ovulation/maturation in females. Gonadal development was classified by light microscopy, following previously established criteria (Asturiano et al., 2000; Begtashi et al., 2004). Animals were sacrificed in accordance with the Spanish (Royal Decree Act 53/2013) and European (2010/63EU) legislations concerning the protection of animals used for experimentation. The protocol used to sacrifice the animals was approved by the Welfare Committee of the IATS (Number of Register 09-0201) supervised by the Ministry of Rural and Marine Environment.

\section{RNApurification and cDNA synthesis}

Total RNA was extracted from the brain of adult fish using the Maxwell® 16 LEV simply RNA Tissue Kit (Promega Corp.) on a Maxwell® 16 Instrument (Promega Corp.) following the manufacturer's protocol. This kit includes an individual DNaseI treatment step in order to discard genomic DNA contamination. Total RNA integrity was assessed by electrophoresis in agarose gel and concentration determined by NanoDrop 2000c spectrophotometer reading (Thermo Scientific). cDNA was synthesized from $2 \mu \mathrm{g}$ of total RNA using random hexamer primers $(2.5 \mathrm{ng} / \mu \mathrm{l})$, dNTPs (0.5 mM of each dNTP) and the SuperScript ${ }^{\mathrm{TM}}$ III Reverse Transcriptase (200U Invitrogen, Carlsbad, CA, USA) in $20 \mu 1$ reactions. Reverse transcription was performed at $50{ }^{\circ} \mathrm{C}$ for $50 \mathrm{~min}$. Reaction was terminated by heating at $70{ }^{\circ} \mathrm{C}$ for $15 \mathrm{~min}$. The RNA used for cDNA synthesis came from pooled tissues of male and female adult sea bass ( $\mathrm{n}=2$ animals/tissue) sampled during the pre-spawning season (October).

Cloning of sea bass leprcDNA and its alternatively-spliced transcripts 
The putative coding sequence for sea bass long form leptin receptor (sblepr) was identified through TBLASTN search on the sea bass genome database (Tine et al., 2014). The amino acid sequence of stickleback (Gasterosteus aculeatus) lepr (Protein ID ENSGACP00000009534.1), taken from Ensembl (http://www.ensembl.org) was used as query. Using brain cDNA as template, three fragments corresponding to the extracellular, intracellular domains and the stop codon region of the sblepr were PCR amplified using the Phusion High-Fidelity DNA Polymerase (Thermo Scientific ${ }^{\mathrm{TM}}$ ) and primer pairs sbsLepr1-sbsLepr2, sbsLepr3-sbsLepr4 and sbsLepr5-sbsLepr6 (Supplementary Table 1), respectively. The following conditions were used: initial denaturation at $98^{\circ} \mathrm{C}$ for $30 \mathrm{~s}$ followed by 30 cycles at $98^{\circ} \mathrm{C}$ for $10 \mathrm{~s}$, annealing temperature at $50{ }^{\circ} \mathrm{C}$ for $30 \mathrm{~s}$ and an extension time based on the polymerase processivity (corresponding to $15-30 \mathrm{~s} / \mathrm{kb}$ of target). To obtain the full sblepr coding sequence, equal amount of each purified fragment $(2.5 \mathrm{ng} / \mu \mathrm{l})$ was used as template in an overlapping PCR reaction using Phusion High-Fidelity DNA Polymerase and the primer pairs sbsLepr1-RysbsLepr6. Improved specificity was achieved by using touchdown PCR. The PCR conditions were an initial denaturation step at $98^{\circ} \mathrm{C}$ for $30 \mathrm{~s}$ followed by 30 cycles at $98^{\circ} \mathrm{C}$ for $10 \mathrm{~s}$, an annealing temperature span starting from $66^{\circ} \mathrm{C}$ to $62^{\circ} \mathrm{C}$ for $30 \mathrm{~s}$ and an extension time based on the polymerase processivity (corresponding to $15-30 \mathrm{~s} / \mathrm{Kb}$ of target). The final step was a single extension cycle at $72^{\circ} \mathrm{C}$ for 7 min. The generated PCR product was gel purified and modified using an Atailing procedure in order to be ligated into the pGEM-T Easy Vector (Promega Corporation, Madison, WI, USA) according to the manufacturer's instruction. Using a sea bass cDNA brain library as template, a PCR was performed where the specific reverse primer sbsLepr7 (Supplementary Table 1), annealing to the extracellular domain of the sblepr, was used in combination with the universal primer FwdSKL which 
anneals to the multiple cloning site of the UNIZAP XR vector, thus amplifying a fragment containing the 5 'region of the sblepr cDNA. The resulting PCR product was inserted into the pGEM-T Easy vector using the same strategy described above.

Most of the alternatively-spliced Lepr transcripts described in the literature are the result of exon removal, particularly exons coding for the intracellular domain. We therefore amplified by PCR the exons coding for the transmembrane and intracellular domains using primers pair sbsExon11 and sbsExon15 (Supplementary Table 1) placed in exon 11 and exon 15 respectively. All PCR products were loaded on agarose gels, separated by electrophoresis, purified and sequenced.

\section{Sequence analysis and phylogeny}

The Sequencher DNA Sequence Analysis software (Gene Code Corporation) was used to assemble sequence contigs. Ig-like C2-type domain and fibronectin type 3 domains were identified through HMMER searches against the Pfam (Punta et al., 2012) database using the predicted amino acid sequence from sea bass sblepr as query. The presence and location of a signal peptide cleavage site was predicted using the SignalP 4.1 server (http://www.cbs.dtu.dk/services/SignalP/). Amino acid sequences were aligned with the CLUSTALW multiple alignment software (Thompson et al., 1994) using default parameters. Phylogenetic analysis was performed with the Molecular

Evolutionary Genetics Analysis (MEGA 5) software (Tamura et al., 2011). The phylogenetic tree was constructed with the neighbor-joining method and 1000 bootstrap permutations. All amino acid sequences used for alignments and phylogenetic analysis were extracted from GenBank (http://www.ncbi.nlm.nih.gov/genbank) and Ensembl (http://www.ensembl.org).

Quantitative real-time PCR ( $q P C R)$ 
The tissue expression patterns of sblepr in different tissues were quantified by qPCR of the cDNA on a Mastercycler ${ }^{\circledR}$ realplex2 (Eppendorf AG, Hamburg, Germany) in ABgene's96-well optical plates (Thermo Fisher Scientific, Inc., Epsom, UK). All samples were run in duplicate. Primers set sbsLepr9-sbsLepr10 (105 pb amplicon size) for sblepr qPCR assay (Supplementary Table 1) was designed using the Primer3 software (http://simgene.com/Primer3). Calibration curves were generated with serial dilutions of cDNA. The efficiencies of PCR reaction was 0.97 . For each $20 \mu \mathrm{l}$ of PCR, optimized amounts of primers $(0.4 \mu \mathrm{M})$ were mixed with $1 \mu \mathrm{l}$ of $\mathrm{RT}$ reaction in $1 \mathrm{x}$ PyroTaqEvaGreen qPCRMix Plus (no ROX; Cultek Molecular Bioline). PyroTaq is activated by a 15 min incubation step at $95{ }^{\circ} \mathrm{C}$ and subsequently qPCR cycling conditions were an initial denaturation step at $95{ }^{\circ} \mathrm{C}$ for $3 \mathrm{~min}$, followed by 40 cycles of denaturation at $95{ }^{\circ} \mathrm{C}$ for $15 \mathrm{~s}$ and annealing-extension at $60{ }^{\circ} \mathrm{C}$ for $1 \mathrm{~min}$. A last melt curve analysis cycle was included to verify the existence of a single qPCR product and ensure the absence of primer-dimer artifacts. The captured data were analyzed by the realplex software (version 2.2). Expression of the $18 \mathrm{~S}$ ribosomal RNA (18S) gene (Felip et al., 2008) (specific primer pairs sbs18S-sbs18S in Supplementary Table 1) in 1:50 diluted cDNA samples was used as a reference gene for data normalization. The $\Delta \Delta \mathrm{Ct}$ method was used to determine the relative mRNA expression (Livak et al., 2001). Expression of sbslepr in testis and ovary are plotted separately. Data from somatic tissues expression in both female and male samples were treated collectively and are plotted as the median value. Data are represented as the relative fold increase respect to the lowest mean expression according to Tinoco et al. (2012).

\section{In situ hybridization}

Males and females ( $n=2-4$ per sex and season) were anesthetised in $0.1 \%$ phenoxy ethanol (Merck Schuchardt OHG, Hohenbrunn, Germany) and then transcardially 
perfused using a peristaltic pump with $50 \mathrm{ml}$ of $0.65 \% \mathrm{NaCl}$ and a fixative solution (4\% paraformaldehyde, $0.1 \mathrm{M}$ phosphate buffer, $\mathrm{pH} 7.4$, and 5\% acid picric). Tissues were collected, fixed overnight in the same fixative solution at room temperature, dehydrated, embedded in paraffin and cut transversally in series at $6 \mu$ m-stick. All sections were mounted onto poly-L-Lysine-coated slides and keep at $4^{\circ} \mathrm{C}$.

In situ hybridization (ISH) for sblepr was performed as described previously (Escobar et al., 2013a) with slight modifications. A 803 pb fragment of sblepr cDNA (nucleotide 644-1447) cloned into the pGEM-T Easy Vector (Promega Corporation, Madison, WI, USA) using the primer pairs sbsLepr3-sbsLepr8 was used for the synthesis of digoxigenin-labeled cRNA probes. The plasmid was linearized with SacII or SalI restrictions enzymes and antisense or sense RNA probes were generated using SP6 or T7 RNA polymerases (Promega, Madison, WI) by in vitro transcription according to the DIG RNA labelling MIX manufacturer's instructions (Roche Applied Science, Indianapolis, IN).

\section{Results}

Cloning and phylogeny of sea bass leptin receptor transcripts

Three transcripts of sea bass leptin receptor were cloned in this study. The longest cDNA is the only transcript that includes all the domains for binding and transduction of the signal and therefore was considered to be the canonical- or long-form of the sea bass leptin receptor, that we named sblepr. The amplified cDNA (GenBank Accession No. KF918755) is 3605 bp long and has an open reading frame (ORF) that codes for a protein of 1149 amino acids (Fig. 1). The first 26 residues are predicted to be the putative signal peptide. Pfam searches and sequence alignment analysis allowed the identification of all functionally important domains conserved among vertebrate Leprs. 
These include two fibronectin type 3 domains, an Ig-like C2-type domain, a pair of repeated tryptophan/serine motifs (WSXWS) in the extracellular domain, two JAK2binding motif boxes and a STAT-binding domain in the intracellular domain (Fig. 1). Amino acids 384-590 in the extracellular domain are predicted to form the leptinbinding domain of sbLepr (Figs.1 and 5). The sbLepr protein has the highest identity to leptin receptor of other fish species (78-34\%) and is only $23 \%$ identical to the human LEPR (Fig. 2).

The evolutionary relationship of the sblepr to other fish, amphibian, and mammalian and avian leptin receptors was inferred by performing a phylogenetic analysis by the neighbor-joining method. The topology of the resulting tree (Fig. 3) shows the sbLepr clustered within the teleost leptin receptor group in $100 \%$ of the bootstrap replicates.

Using a PCR strategy, two shorter sea bass lepr variants were amplified. They were termed isoform 1 and 2 (lepr $r_{I I}$ and $\left.l e p r_{I 2}\right)$, respectively. Generation of these transcripts is based on the usage of different splice sites. Both isoforms encode all the functional domains in the extracellular and intracellular domains but they lack a transmembrane domain and thus the produced proteins should bind leptin and be mostly soluble (soluble binding proteins for leptin; LepBPs) (Fig. 5). Apart from having fewer exons (exons 16 and 17 are missing), the nucleotide sequence of exon 15 is changed due to an alternative splicing junction (Figs.4 and 5). The difference between both isoforms concerns the length of this exon that is $254 \mathrm{bp}$ and $94 \mathrm{bp}$ long in lepr $_{I I}$ and lepr $_{I 2}$, respectively (Fig. 4).

\section{Study of sblepr tissue distribution}

The highest expression levels are observed in the gonads (both testis and ovary), the pituitary gland and the adipose tissue (Fig. 6). The expression of sblepr is relatively 
high also in the muscle and brain, notably elevated in the hypothalamus, followed by the gills, spleen and skin (Fig. 6).

Neuroanatomical localization of sblepr expressing cells in sea bass brain and pituitary

Neither an evident sexual dimorphism, nor obvious differences with reproductive seasons are observed regarding the localization of sblepr expressing cells in the brain and pituitary of European sea bass during their first sexual maturation. Leptin receptor expressing cells are widespread into the forebrain and midbrain of adult male and female sea bass until the caudal portion of the hypothalamus. A major site of expression of sblepr is detected at the level of the telencephalon. Within the periventricular region of the telencephalon, sblepr expressing cells are observed in the subpallial region, where many scattered tiny cells appear to completely cover the dorsal $(\mathrm{Vd})$, ventral $(\mathrm{Vv})$ and post commissural (Vp) parts (Fig. 7B-C-E, 8A). In the pallium, a conspicuous number of sblepr containing cells are remarkably detected in the pars dorsalis (Dd) (Figs. 7B-C, 8D), in the pars lateralis dorsal (Dld) (Figs. 7C-D, 8D), in the subdivision 2, 3 and 4 of the pars medialis (Dm2, Dm3, Dm4), in the pars lateralis ventralis (subdivision 2, Dlv2) and in the nucleus taenia (NT) (Figs. 7C-E, 8B-D). They appear as dense clusters of small positive cells corresponding to the structures of the telencephalon.

Sblepr expressing cells are very evident at the level of the preoptic area (POA) (Figs. $7 \mathrm{D}, 8 \mathrm{E})$ in distinct regions including the parvocellular preoptic nucleus in both its anteroventral and parvocellular components (NPOav, NPOpc) that represent major sites of expression. Also the posterior gigantocellular part of the magnocellular preoptic nucleus (PMgc) (Figs. 7G, 8F) exhibits sblepr mRNA expression under the form of fluorescent for surrounding the very large nuclei characteristic of the magnocellular cells (Fig. 8F). A string of sblepr mRNA is detected in cells located along the boundary of the dorsal habenula (NHd) (Figs. 7G, 8G). In a more caudal region, sblepr mRNA 
expression is observed in the tuberal region, notably into the dorsal (NLTd) (Figs. 7H, 8H), ventral (NLTv) (Figs. 7H-I, 8L-M) and the medial zones (NLTm) (Figs. 7H, 8K-L) parts. Figure $8 \mathrm{~K}$ shows the medial part of the lateral tuberal nucleus, that is placed just above the pituitary stalk, as well as a portion of the pituitary gland (Pit), where sblepr expressing cells are detected (Figs. 7H-I, 8I-K). Lastly, sblepr expressing cells are identified in the posterior recess nucleus (NRP), as shown in figures $7 \mathrm{~J}$ and $8 \mathrm{P}$. Positive cells are observed at the level of the lateral recess starting from its opening, in the ventral part (NRLv), to its more caudal regions (Figs. 7I-J, 8M, O). High expression level of sblepr mRNA is evident into the longitudinal torus (TLo) (Figs. 7J, 8N) and the cerebellar valvula (VCe) including both the granular (G) and molecular (M) layers (Figs. 7H-J, 8N).

\section{Discussion}

The major goal of the present study was to map for the first time, sblepr expression in the brain of a marine teleost as a tool for future studies on the role of leptin in the neuroendocrine function of teleosts. Accordingly we have cloned and analysed the sequence of three leptin receptor transcripts in the European sea bass, an economically valued marine perciform species. The longest cDNA sequence (sblepr) has been proposed as the European sea bass ortholog of the mammalian long form of leptin receptor (LEPR or ObRb), the major responsible for leptin signaling. Thus, this isoform has been further characterized by performing phylogenetic analysis, tissue distribution studies and a fine neuroanatomical localization of sblepr expressing cells in brain and pituitary of adult fish.

Sequence analysis shows that the predicted sbLepr is only $23 \%$ identical to the human LEPR but stretches of high sequence identity can be recognized and they correspond to functionally important protein domains that are known to be essential for ligand binding 
and signal transduction. These conserved structural constrains could partially explain the enhanced release of Lh from dispersed pituitary cells obtained from male sea bass after treatment with mouse recombinant leptin (Peyon et al., 2001). On the other hand, phylogenetic analysis indicate that sblepr clusters with all teleost orthologs so far isolated, being closely evolutionarily related to other perciform.

In fish, multiple alternatively spliced lepr transcripts have been found (Cao et al., 2011; Gong et al., 2013; Rønnestad et al., 2010). They generate shorter isoforms of the receptor and at least some of them act as leptin binding proteins in the blood (Gong et al., 2013). In rainbow trout, fasting resulted in temporal and spatial changes in gene expression and plasma levels of the leptin receptor isoforms (Gong et al., 2013). These data suggest the existence of a complex regulatory mechanism of leptin action in salmonids where soluble leptin receptor isoforms could be involved in modulating the endocrine and/or paracrine output of leptin in target tissues. Both sblepr transcript isoforms isolated in this study have their transmembrane domains missing, while maintaining the extracellular domain, suggesting that they could produce soluble proteins able to bind leptin. They differ from the reported fish leptin receptor shorter isoforms in that they conserve their capability of JAK/STAT signalling. The contribution of European sea bass leptin receptor isoforms to the regulation of the leptin system in this teleost could be a challenging promising future research area.

Analysis of the distribution of the long form of lepr in the CNS of European sea bass by in situ hybridization has not revealed any obvious change according to sex or reproductive season (gonadal resting and mature stages). These results do not exclude the existence of sexual dimorphism in sblepr expression in European sea bass CNS, or the absence of differences regarding gonadal stage. To confirm such result, a quantitative study of the in situ hybridization signal should be performed. Further 
investigation is required to better characterize the contribution of Lepr in European sea bass reproduction. The specific localization of sblepr expressing cells reported in our work is a foundation for this kind of studies. In all animals, sblepr expressing cells were widely observed in the fore- and hindbrain including the most caudal nuclei of the hypothalamus.

Despite of the low sequence homology between fish and mammalian leptin receptor forms, the overall distribution of the main expression sites of lepr in the brain of European sea bass and rat, mouse or human is comparable. For instance, among the regions showing an intense in situ hybridization signal in mouse and rat brains are the arcuate, ventromedial, paraventricular nuclei of the hypothalamus, the hippocampus and the medial habenula (Elmquist et al., 1998; Mercer et al., 1996a; Mercer et al., 1996b). The homologous nuclei in fish are the lateral and anterior tuberal nuclei, the parvocellular preoptic nucleus of the hypothalamus, the medial dorsal telencephalon, and the dorsal habenula, respectively and in the sea bass brain (this work), they also show an evident expression of lepr. Thus, several hypothalamic and extra hypothalamic regions expressing lepr are conserved in vertebrates, suggesting that part of the neural pathways implied in the transmission of leptin functions in vertebrates might be similar.

Starting from the anterior brain of European sea bass, lepr expressing cells were observed in the telencephalic ventral area $(\mathrm{Vd}, \mathrm{Vv})$ and the hypothalamic parvocellular preoptic nucleus, the anteroventral and parvocellular parts (NPOav, NPOpv), being regions that extensively express neuropeptide Y (NPY) in this species (Cerdá-Reverter et al., 2000). Leptin receptor could potentially be coexpressed in NPY containing cells also in the lateral tuberal nucleus (NLT). This region is the fish homolog for the mammalian arcuate nucleus, major hypothalamic center for the control of food intake, feeding behavior and energy homeostasis in vertebrates. Agouti-related protein 1 
(AgRP1) containing neurons have also been reported to be present in the same location in the European sea bass brain (Agulleiro et al., 2014). Thus, although double-labeling studies have not been performed yet, it is likely that NPY neurons of the NLT might express both agrpl and lepr messengers in European sea bass (Agulleiro et al., 2014; Cerdá-Reverter et al., 2000). Moreover, according to the existing literature, POMCderived peptides and CART cells are present in the same hypothalamic region in both mammals and fish (Akash et al., 2014; Gautvik et al., 1996; Koylu et al., 1998). All together, these evidences could suggest that there might be an interplay between leptin and the orexigenic NPY/AGRP and the anorexigenic POMC/CART systems.

The populations of sblepr expressing cells observed in the lateral and ventral parts of the lateral recess nuclei and in the posterior recess probably contain NPY in European sea bass (Cerdá-Reverter at al. 2000). This means that interaction between leptin signaling and NPY neurons could also be occurring at the level of the more caudal tuberal hypothalamus. There is an extensive literature describing NPY as one of the most powerful orexigenic neuropeptide in teleost (Volkoff et al., 2005), acting on the regulation of food intake and energy metabolism at both hypothalamic and pituitary levels. Moreover, NPY plays a role in the stimulation of gonadotropins and growth hormone from the pituitary. In fact, the administration of NPY, both in vivo and in vitro (to dispersed pituitary cells) in European sea bass stimulates Lh release. This NPY effect is dependent on the nutritional status of the animal at the moment of the treatment (Cerdá-Reverter et al., 1999; Peyon et al., 2001). From this finding it is clear that NPY acts directly on Lh secreting gonadotrophs, but it cannot be excluded an upstream role of NPY firing from the hypothalamus. In fact, NPY expressing cells are also located at the level of the preoptic area, where gonadotropin releasing hormone immunoreactive cells are well characterized in European sea bass brain (González-Martínez et al., 2002). 
Our results clearly show the presence of sblepr containing cells at both brain (preoptic region) and pituitary levels. This is in line with the hypothesis that NPY is mediating the leptin effect on the modulation of feeding behavior and reproductive functions. Such an assumption has already been proposed by Peyon and collaborators when they observed that a co-treatment with leptin and NPY was more potent in stimulating Lh and somatolactin release in late pubertal sea bass pituitary cells than when leptin or NPY alone (Peyon et al., 2001, 2003).

Also worth of mentioning is the fact that $100 \%$ of the somatostatin immunoreactive cells of the mediobasal hypothalamic (nucleus lateralis tuberis) neurons express kisspeptin receptors (Escobar et al., 2013b). Somatostatin inhibits the secretion of growth hormone from pituitary somatotropes in both mammals and teleost (Burgus et al., 1973; Canosa et al., 2005; Fryer et al., 1979; Marchant et al., 1987), leading us to propose possible interactions between the growth/metabolic and the reproductive axis. In fact, in male sea bass fish size and/or energy level are very likely a permissive condition to attain the threshold of hormone synthesis and release needed to achieve its reproductive function (Carrillo et al., 2015).

Altogether these observations reinforce the hypothesis that leptin may regulate the reproductive and somatic growth processes by interacting with several hormonal systems located in the main hypophysiotrophic areas in the sea bass CNS. This is supported by the tissue expression pattern study, showing the highest sblepr expression levels in organs connected to the reproductive function (brain, pituitary and gonads) and somatic growth (muscle).

In conclusion, we report on the cloning and sequence analysis of three transcripts for sea bass leptin receptor. Two short variants are proposed to produce soluble proteins 
able to bind leptin, whereas the long form, termed sblepr, is likely the ortholog of human $L E P R$ gene.

To the best of our knowledge this work is the first to report the neuroanatomical organization of the long form of leptin receptor expressing cells in a perciform. The CNS localization of sblepr suggests a role of leptin signaling in multiple key physiological processes. Notably, the neural pathways controlling feeding intake, energy homeostasis and reproduction express sblepr. These functions are tightly linked in most fish species, as well as in European sea bass, since gonad maturation is dependent on the nutritional status. In fact, European sea bass is a seasonal spawner who gradually reduces food intake during the period of gonadal development until reaching minimal values during the spawning season (Zanuy and Carrillo, 1985). All this places leptin among the best candidates to link appetite, metabolic rate, and energy stores with the neuroendocrine control of reproduction at least in European sea bass. Our hypothesis needs to be sustained by further research including, for example, exogenous leptin administration under different nutritional regimes.

\section{Acknowledgments}

We would like to thank the Animal Husbandry Service at IATS for technical assistance and sampling with the animals. This research was supported by UE project FP7222719-1 (LIFECYCLE), project PROMETEO/11/2014/051 (REPROBASS) from the Valencian Regional Government and CSD2007-00002 (AQUAGENOMICS) from the Ministry of Science and Innovation (MICINN), Spain. S.E was sponsored by a JAE fellowship from CSIC (Spain) and a CONICYT predoctoral fellowship from Chile. 


\section{References}

Agulleiro, M.J., Cortés R, Leal E, Ríos D, Sánchez E, Cerdá-Reverter J.M., 2014. Characterization, tissue distribution and regulation by fasting of the agouti family of peptides in the sea bass (Dicentrarchus labrax). Gen. Comp. Endocrinol. 205, 251-259.

Akash, G., Kaniganti, T., Tiwari, N.K., Subhedar, NK., Ghose, A., 2014. Differential distribution and energy status-dependent regulation of the four CART neuropeptide genes in the zebrafish brain. J. Comp. Neurol. 522, 2266-2285.

Allison, M.B., Myers, M.G., 2014. 20 YEARS OF LEPTIN: Connecting leptin signaling to biological function. J. Endocrinol. 223, 25-35.

Angotzi, A.R., Stefansson, S.O., Nilsen, T.O., Rathore, R.M., Rønnestad, I., 2013. Molecular cloning and genomic characterization of novel Leptin-like genes in salmonids provide new insight into the evolution of the Leptin gene family. Gen. Comp. Endocrinol. 187, 48-59.

Asturiano, J.F., Sorbera, L.A., Ramos, J., Kime, D.E., Carrilo, M., Zanuy, S., 2000. Hormonal regulation of the European sea bass reproductive cycle: an individualized female approach. J. Fish. Biol. 56, 1155-1172.

Begtashi, I., Rodríguez, L., Moles, G., Zanuy, S., Carrillo, M., 2004. Long-term exposure to continuous light inhibits precocity in juvenile male European sea bass (Dicentrarchus labrax, L.). I. Morphological aspects. Aquaculture 241, 539-559.

Broberger, C., Johansen, J., Johansson, C., Schalling, M., Hökfel,t T., 1998. The neuropeptide Y/agouti gene-related protein (AGRP) brain circuitry in normal, 
anorectic, and monosodium glutamate-treated mice. Proc. Natl. Acad. Sci. U S A.95, 15043-15048.

Burgus, R., Ling, N., Butcher, M., Guillemin, R., 1973. Primary structure of somatostatin, a hypothalamic peptide that inhibits the secretion of pituitary growth hormone. Proc. Natl. Acad. Sci. U S A. 70, 684-688.

Canosa, LF., Unniappan, S., Peter, R.E., 2005. Periprandial changes in growth hormone release in goldfish: role of somatostatin, ghrelin, and gastrin-releasing peptide. Am. J. Physiol. Regul. Integr. Comp. Physiol. 289, 125-133.

Carrillo, M.,Espigares, F.,Felip, A.,Escobar, S.,Molés, G.,Alvarado, V.,Gómez A.,Zanuy, S., 2015.Updating control of puberty in male European sea bass: a holistic approach. Gen. Comp. Endocrinol. 221, 42-53.

Cao, Y.B., Xue, J.L., Wu, L.Y., Jiang, W., Hu, PN., Zhu, J., 2011. The detection of 3 leptin receptor isoforms in crucian carp gill and the influence of fasting and hypoxia on their expression. Domest. Anim. Endocrinol. 41, 74-80.

Cerdá-Reverter, J.M., Sorbera, L.A., Carrillo, M., Zanuy, S., 1999. Energetic dependence of NPY-induced LH secretion in a teleost fish (Dicentrarchus labrax). Am. J. Physiol. 277, 1627-1634.

Cerdá-Reverter, J.M., Anglade, I., Martínez-Rodríguez, G., Mazurais, D., MuñozCueto, J.A., Carrillo, M., Kah, O., Zanuy, S., 2000. Characterization of neuropeptide $\mathrm{Y}$ expression in the brain of a perciform fish, the sea bass (Dicentrarchus labrax). J. Chem. Neuroanat. 19, 197-210.

Cerdá-Reverter, J.M., Zanuy S, Muñoz-Cueto, J.A., 2001a. Cytoarchitectonic study of the brain of a perciformspecies, the Sea Bass (Dicentrarchus labrax).I. The Telencephalon. J. Morphol.247, 217-228. 
Cerdá-Reverter, J.M., Zanuy, S., Muñoz-Cueto, J.A., 2001b.Cytoarchitectonic study of the brain of a perciformspecies, the Sea Bass (Dicentrarchus labrax).II. The Diencephalon. J. Morphol.247, 229-251.

Elmquist, J.K., Bjørbæk, C., Ahima, R.S., Flier, J.S., Saper, C.B. 1998. Distributions of leptin receptor mRNA isoforms in the rat brain. J. Comp. Neurol. 395, 535-547.

Escobar, S., Felip, A., Gueguen, M.M., Zanuy, S., Carrillo, M., Kah, O., Servili, A., 2013a. Expression of kisspeptins in the brain and pituitary of the european sea bass (Dicentrarchus labrax). Comp. Neurol. 521, 933-948.

Escobar, S., Servili, A., Espigares, F., Gueguen, M.M., Brocal, I., Felip, A., Gómez, A., Carrillo, M., Zanuy, S., Kah, O., 2013b. Expression of kisspeptins and kiss receptors suggests a large range of functions for kisspeptin systems in the brain of the european sea bass. PLoS ONE 8:e70177.

Felip, A., Zanuy, S., Muriach, B., J.M., Carrillo, M., 2008. Reduction of sexual maturation in male Dicentrarchus labrax by continuous light both before and during gametogenesis. Aquaculture 275, 347-355.

Frøiland E., Murashita K., Jørgensen E.H., Kurokawa T., 2010. Leptin and ghrelin in anadromous Arctic charr: cloning and change in expressions during a seasonal feeding cycle. Gen. Comp.Endocrinol165, 136-143.

Fryer, J.N., Nishioka, R.S., Bern, H.A., 1979. Somatostatin inhibition of teleost growth hormone secretion. Gen. Comp.Endocrinol.39, 244-246.

Gautvik, K.M., de Lecea, L., Gautvik, V.T., Danielson, P.E., Tranque, P., Dopazo, A., Bloom, F.E., Sutcliffe, J.G., 1996. Overview of the most prevalent hypothalamus-specific mRNAs, as identified by directional tag PCR subtraction. Proc. Natl. Acad. Sci. U S A. 93, 8733-8738. 
Gong, N., Einarsdottir, I.E., Johansson, M., Björnsson, B.T., 2013. Alternative splice variants of the rainbow trout leptin receptor encode multiple circulating leptinbinding proteins. Endocrinology 154, 2331-2340.

González-Martínez, D., Zmora, N., Mañanos, E., Saligaut, D., Zanuy, S., Zohar, Y., Elizur, A., Kah, O., Muñoz-Cueto, J.A., 2002. Immunohistochemical localization of three different prepro-GnRHs in the brain and pituitary of the European sea bass (Dicentrarchus labrax) using antibodies to the corresponding GnRH-associated peptides. J. Comp. Neurol. 446, 95-113.

Gorissen, M., Bernier, N.J., Nabuurs, S.B., Flik, G., Huising, M.O., 2009. Two divergent leptin paralogues in zebrafish (Danio rerio) that originate early in teleostean evolution.J. Endocrinol. 201, 329-339.

Gorissen, M., Flik, G., 2014. Leptin in teleostean fish, towards the origins of leptin physiology. J. Chem. Neuroanat. 61-62, 200-206.

Koylu, E.O., Couceyro, P.R., Lambert, P.D., Kuhar, M.J., 1998. Cocaine- and amphetamine-regulated transcript peptide immunohistochemical localization in the rat brain. J. Comp. Neurol. 391, 115-132.

Kurokawa, T., Murashita, K., 2009. Genomic characterization of multiple leptin genes and a leptin receptor gene in the Japanese medaka, Oryzias latipes. Gen. Comp. Endocrinol. 161, 229-237.

Lee, G.H., Proenca, R., Montez, J.M., Carroll, K.M., Darvishzadeh, J.G., Lee, J.I., Friedman, J.M., 1996. Abnormal splicing of the leptin receptor in diabetic mice. Nature 379, 632-635.

Liu, Q., Chen, Y., Copeland, D., Ball, H., Duff, R.J., Rockich, B., Londraville, R.L., 2010. Expression of leptin receptor gene in developing and adult zebrafish. Gen. Comp. Endocrinol. 166, 346-355. 
Livak, K.J., Schmittgen, T.D., 2001. Analysis of relative gene expression data using realtime quantitative PCR and the $2^{-\Delta \Delta C}$ Tmethod. Methods $25,402-8$.

Marchant, T., Fraser, R., Andrews, P., Peter, R., 1987. The influence of mammalian and teleost somatostatins on the secretion of growth hormone from goldfish (Carassius auratus L.) pituitary fragments in vitro. Regul. Pept. 17, 41-52.

Mercer, J.G, Hoggard, N., Williams, L., Lawrence, C., Hannah, L., Morgan, P., Trayhurn, P., 1996a. Coexpression of leptin receptor and preproneuropeptide Y mRNA in arcuate nucleus of mouse hypothalamus. J. Neuroendocrinol. 10, 733736.

Mercer, J.G., Hoggard, N., Williams, L.M., Lawrence, C.B., Hannah, L.T., Trayhurn, P., 1996b. Localization of leptin receptor mRNA and the long form splice variant $(\mathrm{Ob}-\mathrm{Rb})$ in mouse hypothalamus and adjacent brain regions by in situ hybridization. FEBS Letters 387, 113-116.

Park, H.K., Ahima, R.S., 2014. Physiology of leptin: energy homeostasis, neuroendocrine function and metabolism. Metabolism 64, 24-34.

Peyon, P., Zanuy, S., Carrillo, M., 2001. Action of leptin on in vitro luteinizing hormone release in the european sea bass (Dicentrarchus labrax). Biol. Reprod. $65,1573-1578$.

Peyon, P., Vega-Rubin de Celis, S., Gómez-Requeni, Zanuy, S., Pérez-Sánchez, J., Carrillo, M., 2003.In vitro effect of leptin on somatolactin release in the European sea bass (Dicentrarchuslabrax): dependence on the reproductive status and interaction with NPY and GnRH. Gen. Comp. Endocrinol. 133, 284292. 
Prokop, J.W., Duff, R.J., Ball, H.C., Copeland, D.L., Londraville, R.L., 2012. Leptin and leptin receptor: Analysis of a structure to function relationship in interaction and evolution from humans to fish. Peptides 38, 326-336.

Punta, M., Coggill, P.C., Eberhardt, R.Y., Mistry, J., Tate, J., Boursnell, C., Pang, N., Forslund, K., Ceric, G., Clements, J., Heger, A., Holm, L., Sonnhammer, E.L.L., Eddy, S.R., Bateman, A., Finn, R.D., 2012. The Pfam protein families database. Nucleic. Acids. Res. 40, 290-301.

Rønnestad, I., Nilsen, T.O., Murashita, K., Angotzi, A.R., Gamst Moen, A.G., Stefansson, S.O., Kling, P., Thrandur Björnsson, B., Kurokawa, T., 2010. Leptin and leptin receptor genes in Atlantic salmon: Cloning, phylogeny, tissue distribution and expression correlated to long-term feeding status. Gen. Comp. Endocrinol. 168, 55-70.

ShpilmanM., Hollander-CohenL., VenturaT., GertlerA., Levavi-SivanB., 2014. Production, gene structure and characterization of two orthologs of leptin and a leptin receptor in tilapia. Gen. Comp. Endocrinol. 207, 74-85.

Tamura, K., Peterson, D., Peterson, N., Stecher, G., Nei, M., Kumar, S., 2011. MEGA5: Molecular evolutionary genetics analysis using maximum likelihood, evolutionary distance, and maximum parsimony methods. Mol. Biol. Evol. 28, 2731-2739.

Tartaglia, L. 1997. The Leptin receptor. J. Bio.1 Chem. 7, 6093-6096.

Thompson, J.D., Higgins, D.G., Gibson, T.J., 1994. CLUSTAL W: improving the sensitivity of progressive multiple sequence alignment through sequence weighting, position-specific gap penalties and weight matrix choice. Nucleic. Acids. Res. 22, 4673-4680. 
Tine, M., Kuhl, H., Gagnaire, P.A., Louro, B., Desmarais, E., Martins, R.S.T., Hecht, J., Knaust, F., Belkhir, K., Klages, S., Dieterich, R., Stueber, K., Piferrer, F., Guinand, B., Bierne, N., Volckaert, F.A.M., Bargelloni, L., Power, D.M., Bonhomme, F., Canario, A.V.M., Reinhardt, R., 2014. European sea bass genome and its variation provide insights into adaptation to euryhalinity and speciation. Nat. Commun. 5, 1-10.

Tinoco, A.N., Nisembaum, L.G., Isorna, E., Delgado, M.J., de Pedro, N., 2012. Leptins and leptin receptor expression in the goldfish (Carassius auratus). Regulation by food intake and fasting/overfeeding conditions. Peptides 34, 329-335.

Trombley S., Mustafa A., Schmitz M., 2014. Regulation of the seasonal leptin and leptin receptor expression profile during early sexual maturation and feed restriction in male Atlantic salmon (Salmo salar L.) parr. Gen.Comp. Endocrinol. 204, 60-70.

Trombley, S., Rocha, A., Schmitz, M., 2015. Sex steroids stimulate leptin gene expression in Atlantic salmon parr hepatocytes in vitro. Gen. Comp. Endocrinol. $221,156-164$.

Volkoff, H., Canosa, L.F., Unniappan, S., Cerdá-Reverter, J.M., Bernier, N.J., Kelly, S.P., Peter, RE., 2005. Neuropeptides and the control of food intake in fish. Gen. Comp. Endocrinol. 142, 3-19.

Wang, M.Y., Yan, T.Z., Newgard, C.B., Unger, R.H., 1996. A novel leptin receptor isoform in rat. FEBS Letters 392, 87-90.

Wang, Y., Jones, Voy, B., Urs, S., Kim, S., Soltani-Bejnood, M., Quigley, N., Heo, Y.R., Standridge, M., Andersen, B., Dhar, M., Joshi, R., Wortman, P., Taylor, J.W., Chun, J., Leuze, M., Claycombe, K., Saxton, A.M., Moustaid-Moussa, N., 
2004. The Human fatty acid synthase gene and de novo lipogenesis are coordinately regulated in human adipose tissue.J. Nutr. 134, 1032-1038.

Weil, C., Le Bail, P.Y., Sabin, N., Le Gac, F., 2003. In vitro action of leptin on FSH and LH production in rainbow trout (Onchorynchus mykiss) at different stages of the sexual cycle. Gen. Comp. Endocrinol. 130, 2-12.

Zanuy, S., Carrillo, M., 1985. Annual cycles of growth, feeding rate, gross conversion efficiency and hematocrit levels of sea bass (Dicentrarchus labrax L.) adapted to two different osmotic media. Aquaculture 44, 14-25. 


\section{LIST OF ABREVIATTIONS ON SEA BASS BRAIN}

CCe corpus of the cerebellum; CE cerebellum; CP central posterior thalamic nucleus; Dlp lateral posterior part of the dorsal telencephalic area; $\mathrm{Vv}$ ventralnuclei of the ventral telencephalon; Vc central nuclei of the ventral telencephalon; Dm2 subdivision 2 of the medial dorsal telencephalic area; Dm3 subdivision 3 of the medial dorsal telencephalic area; Dp posterior portion of the dorsal telencephalon; E entopeduncular nucleus; HAco habenular commissure; I intermediate thalamic nucleus; IL inferior lobe of the hypothalamus; MaoT marginal optic tract; NAPv anterior periventricular nucleus; NAT anterior tuberal nucleus; NDLIl lateral part of the diffuse nucleus; NDLIm medial part of the diffuse nucleus of the inferior lobe; NGT tertiary gustatory nucleus; NH habenular nucleus; NHd dorsal habenular nucleus; NHv ventral habenular nucleus; NLT lateral tuberal nucleus; NLTi inferior part of the lateral tuberal nucleus; NLTm medial part of the lateral tuberal nucleus; NLTv ventral part of the lateral tuberal nucleus; nMLF nucleus of the medial longitudinal fasciculus; NPC central pretectal nucleus; NPGa anterior preglomerular nucleus; NPGm medial preglomerural nucleus; PI pineal gland; NPOav anteroventral part of the parvocelullar preoptic nucleus; NPOpc parvocellular part of paraventricular organ; nPVO nucleus of the paraventricular organ; NRL nucleus of the lateral recess; NRLd dorsal part of the nucleus of the lateral recess; NRL1 lateral part of the nucleus of the lateral recces; NRLv ventral part of the nucleus of the lateral recess; NRP nucleus of the posterior recces; NSV nucleus of the saccus vasculosus; OB olfactory bulbs; OpN optic nerve; OT optic tectum; P pituitary; PMgc gigantocellular part of the magnocellular preoptic nucleus; POA preoptic area; PPd dorsal periventricular pretectal nucleus; PPv ventral periventricular pretectal nucleus; PSp parvocellular superficial pretectal nucleus; PVO paraventricular organ; SV saccus vasculosus; TEG tegmentum; TEL telencephalon; TLa nucleus of the torus lateralis; 
TLo torus longitudinalis; TPp periventricular nucleus of the posterior tuberculum; VCe valvula of the cerebellum; VL ventrolateral thalamic nucleus; VM ventromedial thalamic nucleus; VOT ventral optic tract. 


\section{Figure legends}

Fig. 1. Nucleotide and deduced amino acid sequence of the sblepr c DNA. Numbers on the left refer to position of the amino acid (top) and the nucleotide residues (bottom). Amino acid numbering begins with the proposed initial methionine. The predicted signal peptide is marked with a dashed and dotted line. The Ig-like C2-type domain (Pfam identification number PF06328) is indicated by a grey box. The two cysteine residues in this domain that are supposed to form a disulphide bridge are marked with an asterisk. Two fibronectin type 3 domains also identified by Pfam searches (PF00041) are underlined. The putative leptin-binding domain is in bold italicized text. Other conserved motifs for LepR (WSXWS tryptophan/ serine motifs; JAK2 binding motif boxes and STAT-binding motif box) are shown. The nucleotide sequence has been submitted to the GenBank and is available under the Accession No.KF918755.

Fig. 2. Amino acid sequence alignment of the leptin binding domain of human and fish Lepr proteins. Sequences were aligned using ClustalW. Identical amino acids are highlighted in blackand similar $(80 \%)$ in grey. Species abbreviations and GenBank/ RefSeq/ Ensemb1 accession numbers are: Hsa, Homo sapiens (AAA93015) Dla, Dicentrarchus labrax (KF918755); Tru, Takifugu rubripes (BAG67079); Eco, Epinephelus coioides (AFU55262); Cca, Carassius carassius (ADZ75460); Ome, Oryzias melastigma (ABC86922); Ola, Oryzias latipes (BAH24203); Dre, Danio rerio (XP_005165935); Ssa, Salmon salar (BAI23197); Omy, Oncorhynchus mykiss (AGC55253); Tfu, Tachysurus fulvidraco (AFO67946).The numbers on the right refer to amino acid position on the complete sequences.

Fig. 3. Phylogenetic tree of Lepr. Tree was generated using an alignment of complete protein sequences. Bootstrap values, number of times each branching was obtained, are 
indicated as a percentage out of 1000 bootstrap iterations. GenBank/RefSeq/Ensembl accession numbers of the sequences are: Oryzias melastigma, ABC86922; Oryzias latipes, BAH24203; Xiphophorus maculatus, ENSXMAP00000002254; Oreochromis mossambicus, AGT28753; Epinephelus coioides, AFU55262; Takifugu rubripes, BAG67079; Dicentrarchus labrax, KF918755; Salmo salar, BAI23197; Oncorhynchus mykiss, AGC55253; Tachysurus fulvidraco, AFO67946; Ctenopharyngodon idella, AFU35431; Danio rerio, XP_005165935; Carassius carassius, ADZ75460; Xenopus (Silurana) tropicalis, ABD63000; Mus musculus, AAC52408; Rattus norvegicus, AAC52587; Homo sapiens, AAA93015; Macaca mulatta, AAF34683; Sus scrofa, AAC61766; Bos taurus, ENSBTAP00000007764; Anser anser, AEE61372; Anas platyrhynchos, ENSAPLP00000015829; Meleagris gallopavo, ENSMGAP00000012466; Gallus gallus, AAF31355.

Fig. 4. Nucleotide and deduced amino acid sequence of the two sblepr cDNA isoforms. Numbers on the left refer to position of the nucleotide residues. The alternative exon 15 , exon $15^{\prime}$, short (15'-94bp) and large (15'-254bp) versions is double underlined.

Fig. 5. Drawing of the gene structure of the coding region of long-form sblepr and the two amplified shorter isoforms, sblepr $_{I I}$ and sblepr $_{I 2}$. (A) The long form sblepr includes an extracellular domain containing a leptin-binding domain and other conserved features (e.g.twoWSXWS motifs). The extracellular domain is followed by a transmembrane domain (TM) and an intracellular domain that includes two JAK2 binding motif boxes and a STAT-binding motif box. (B) The sblepr $I I$ has an alternative exon 15 , the exon $15^{\prime}$ that in this isoform is $254 \mathrm{bp}$ long and exons 16 and 17 are missing. (C) The isoform sblepr ${ }_{I 2}$ has a shorter $(94 \mathrm{bp})$ version of the alternative exon $15^{\prime}$ and exons 16 and 17 are missing. In both isoforms the TM, encoded by exon 17, is 
missing. The annotation assembly from the sea bass genome database (Tine et al., 2014) was used to retrieve information regarding introns sequence.

Fig. 6. Tissue distribution of the leptin receptor (sblepr) in sea bass. Data represents the relative fold increase calculated from $\mathrm{qPCR}$ using $\Delta \Delta \mathrm{Ct}$ method after standardization with $18 S$ gene. The fold increase is respect to the lowest mean expression value (gut) that was set as one. Testis and ovary are depicted separately.

Fig. 7. Schematic drawings of transverse sections taken from the brain atlas of the European sea bass (Cerdá-Reverter et al., 2001a;b) summarizing a representative distribution of sblepr expressing neurons in female (Fe) and male (Ma) European sea bass during the breeding $(\mathrm{Br})$ and non-breeding $(\mathrm{NBr})$ seasons. (A) Sideview of the sea bass brain indicating the levels of the transver sesections. (B-J) Black dots indicate the location of sblepr expressing sblepr cells. Scale bar $=1 \mathrm{~mm}$.

Fig. 8. In situ hybridization of sblepr on transverse sections. Cells expressing sblepr (arrowheads) in the ventral (Vv) nuclei of the ventral telencephalonVd (Fig. 8A). Cells expressing sblepr (arrowheads) in the pars lateralis ventralis (subdivision 2, Dlv2), in the subdivision 2, 3 and 4 of the pars medialis (Dm2, Dm3, Dm4), the telencephalic dorsal area in the pars dorsalis (Dd) and in the pars lateralis dorsal (Dld) (Figs. 8B-D). Numerous cells expressing sblepr (arrowheads) were located at the level of the preoptic area (POA) (Fig. 8E) and also the more posterior gigantocellular part of the magnocellular preoptic nucleus (PMgc) (Fig. 8F). Cells expressing sblepr (arrowheads) along the boundary of the dorsal habenula (NHd) (Fig. 8G).Numerous cells expressing sblepr (arrowheads) were located at the dorsal part of the lateral tuberal nucleus (NLTd) (Fig. $8 \mathrm{H}$ ) along the third ventricle of the hypothalamus. Notable expression of sblepr in the pituitary (Figs. 8I-J), the lateral tuberal zone, the ventral (NLTv) and the medial (NLTm) parts (Figs. 8K-M). High expression of sblepr is evident in the longitudinal 
torus (TLo) (Fig. $8 \mathrm{~N}$ ) and at the level of the lateral recess starting from its opening, in the ventral part (NRLv), until its lateral region (NRLl), defining the boundary of these recesses (Figs. 8M, O). Cells expressing sblepr (arrowheads) in the posterior recess nucleus (NRP) (Fig. 8P). A (NBr-Fe); B-D (Br-Ma); E (NBr-Ma); F (NBr-Fe); G-H $(\mathrm{NBr}-\mathrm{Fe}) ; \mathrm{I}-\mathrm{J}(\mathrm{Br}-\mathrm{Fe}) ; \mathrm{K}-\mathrm{L}(\mathrm{Br}-\mathrm{Ma})$ and N-P (NBr-Ma). Bar $=25 \mu \mathrm{m}$ 
Fig. 1

ATCAAACTCAGACTCAACAATGGAAAGGCAACTCTGACAGATCTTCACTGAGGATTTTAAACTTCCCCTGTATGACCCCTGGA CACGAAACCGCAAGAGT

$\mathrm{M}$ T TT M V R $\mathrm{S}$ V

TCTTTTTCCACTGAGATTCACCCCAGCCAAATCCCTGCAAGGCCATGCTCATGCTATGACCACTACAATGGTTCGGTCTGTAA TGTTGACAGTCCTGATG

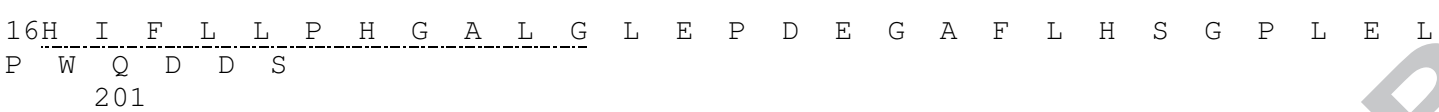
CATATTTTCCTGTTGCCCCATGGTGCTCTGGGTTTGGAGCCAGATGAGGGAGCCTTCCTCCATTCAGGTCCCTTGGAGCTCCC CTGGCAGGATGACTCAC

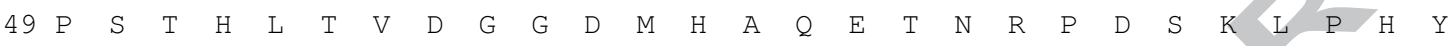
$\begin{array}{lllllll}S & H & C & N & F & R & S\end{array}$ 301

CTTCAACCCACCTCACTGTGGACGGAGGAGACATGCACGCACAGGAGACAAACCGCCCTGATTCAAAACTCCCACACTATTCT CACTGCAACTTCAGGAG

$\begin{array}{llllllllllllllllllllllllllllllll}83 & \mathrm{~S} & \mathrm{~T} & \mathrm{~N} & \mathrm{~N} & \mathrm{~S} & \mathrm{R} & \mathrm{P} & \mathrm{H} & \mathrm{E} & \mathrm{L} & \mathrm{S} & \mathrm{S} & \mathrm{G} & \mathrm{T} & \mathrm{C} & \mathrm{L} & \mathrm{N} & \mathrm{I} & \mathrm{L} & \mathrm{C} & \mathrm{R} & \mathrm{I} & \mathrm{D} & \mathrm{E} & \mathrm{N} & \mathrm{W}\end{array}$

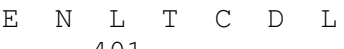
401

CTCGACAAACAATTCACGTCCTCATGAGCTCTCAAGCGGCACCTGTTTGAACATACTGIGCAGAATTGATGAAAACTGGGAAA ATCTAACTTGTGACCTT

$\begin{array}{lllllllllllllllllllllllllllllll} & 116 & Q & \mathrm{~S} & \mathrm{H} & \mathrm{G} & \mathrm{P} & \mathrm{P} & \mathrm{S} & \mathrm{T} & \mathrm{T} & \mathrm{L} & \mathrm{D} & \mathrm{A} & \mathrm{G} & \mathrm{L} & \mathrm{M} & \mathrm{K} & \mathrm{V} & \mathrm{S} & \mathrm{L} & \mathrm{Q} & \mathrm{R} & \mathrm{L} & \mathrm{M} & \mathrm{S} & \mathrm{Q} & \mathrm{K}\end{array}$

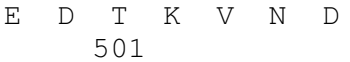

CAGTCTCATGGCCCACCATCTACCACTCTGGATGCTGGTCTCATGAAAGTTAGCTTACAGCGTCTGATGTCCCAGAAAGAGGA CACCAAGGTGAACGACG

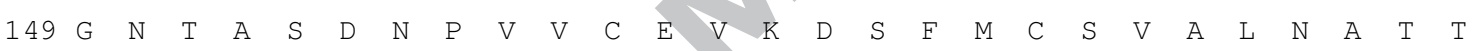
$\begin{array}{lllllll}S & F & V & I & V & V & T\end{array}$

GGAATACTGCATCCGATAATCCTGTCGTCTGTGAAGTGAAGGATTCCTTCATGTGCTCAGTTGCTCTCAATGCTACAACAAGC TTIGTCATCGTGGTAAC

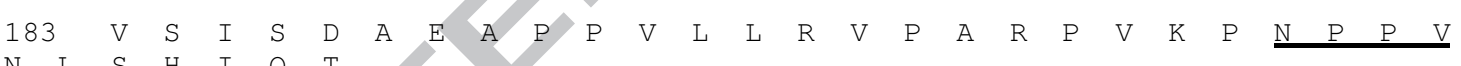

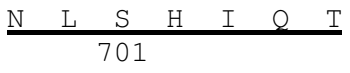

CGTCAGCATCTCCGACGCCGAGGCTCCGCCAGTCCTCCTCAGAGTTCCTGCCCGACCTGTGAAACCAAACCCTCCAGTCAACC TGTCACATATCCAGACC

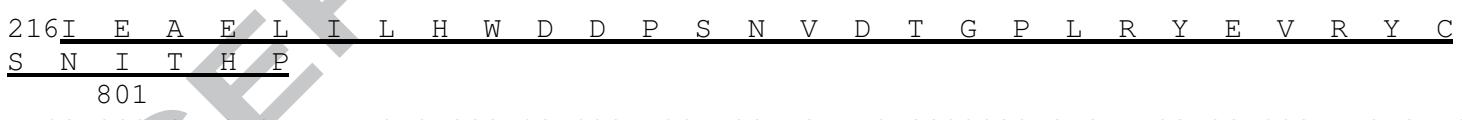
ATCGAGGCAGAACTGATT TTACACTGGGACGACCCATCCAACGTTGATACTGGCCCGCTGAGATACGAGGTCCGATACTGT TC CAACATCACTCATCCAG

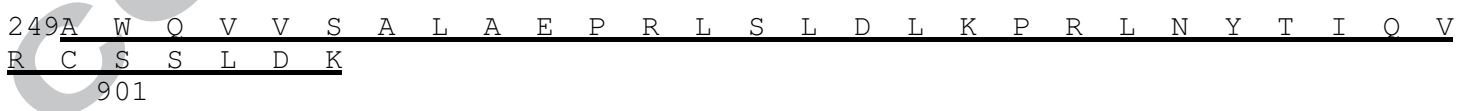
CCTGGCAGGTGGTGTCTGCACTTGCAGAGCCCCGGTTATCTCTGGATCTGAAGCCCAGACTGAATTACACCATCCAGGTTCGC TGCTCCAGCCTGGACAA

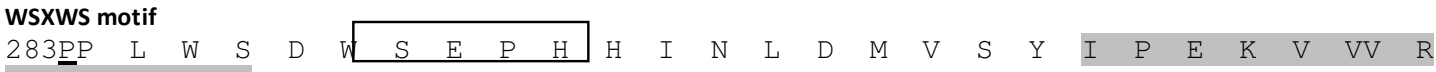

$\begin{array}{lll}P & \bar{G} & \mathrm{~N} \\ 1001 & \mathrm{~V}\end{array}$

GCCTCCACTGTGGAGTGACTGGAGTGAACCTCACCATATCAACCTGGACATGGTGAGCTACATCCCGGAGAAAGTGGTGGTGC GACCGGGGGAGAATGTA

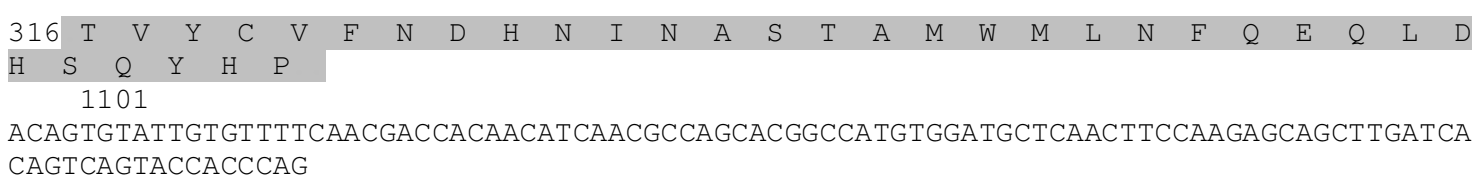




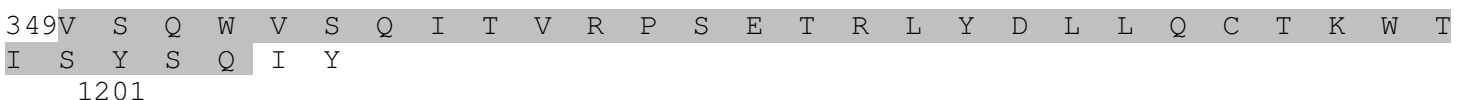
TCAGCCAGTGGGTCAGCCAGATCACAGTGCGACCTTCGGAGACACGATTGTATGACCTGCTGCAGTGCACGAAGTGGACCATC TCATACAGTCAGATCTA

$\begin{array}{lllllllllllllllllllllllllllllll}383 & V & E & G & A & S & I & \boldsymbol{N} & I & \boldsymbol{N} & \boldsymbol{C} & \boldsymbol{E} & \boldsymbol{T} & \boldsymbol{N} & \boldsymbol{G} & \boldsymbol{D} & \boldsymbol{I} & \boldsymbol{D} & \boldsymbol{A} & \boldsymbol{M} & \boldsymbol{D} & \boldsymbol{C} & \boldsymbol{R} & \boldsymbol{W} & \boldsymbol{K} & \boldsymbol{N} & \boldsymbol{S} \\ \boldsymbol{V} & \boldsymbol{W} & \boldsymbol{T} & \boldsymbol{Q} & \boldsymbol{L} & \boldsymbol{K} & \boldsymbol{L} & & & & & & & & & & & & & & & & & & & & & \end{array}$ 1301

TGTAGAAGGAGCGTCTATAAATATAAACTGTGAAACCAACGGCGATATCGATGCTATGGACTGTAGGTGGAAGAACTCAGTGT GGACTCAACTCAAATTG

$\begin{array}{llllllllllllllllllllllllllll}416 \boldsymbol{K} & \boldsymbol{S} & \boldsymbol{W} & \boldsymbol{W} & \boldsymbol{A} & \boldsymbol{N} & \boldsymbol{L} & \boldsymbol{P} & \boldsymbol{C} & \boldsymbol{D} & \boldsymbol{V} & \boldsymbol{M} & \boldsymbol{E} & \boldsymbol{E} & \boldsymbol{R} & \boldsymbol{E} & \boldsymbol{R} & \boldsymbol{A} & \boldsymbol{G} & \boldsymbol{E} & \boldsymbol{N} & \boldsymbol{V} & \boldsymbol{G} & \boldsymbol{E} & \boldsymbol{M} & \boldsymbol{G} & \boldsymbol{P}\end{array}$ $\begin{array}{llllll}D & C & L & Q & V & R\end{array}$ 1401

AAATCCTGGTGGGCTAACCTGCCATGTGATGTGATGGAGGAGAGGGAAAGAGCAGGCGAGAATGTGGGGGAGATGGGACCTGA TTGCCTGCAGGTTCGAT

$\begin{array}{llllllllllllllllllllllllllllll}449 & S & Q & Q & K & T & C & H & I & Q & P & L & R & M & N & C & Y & K & L & W & L & E & M & P & S & R & L & G\end{array}$ $\begin{array}{lllllll}P & I & R & S & K & P & I\end{array}$

1501

CCCAGCAGAAAACCTGCCACATCCAGCCCCTGAGAATGAACTGCTACAAGCTGTGGCTGGAAATGCCGTCTCGGC TTGGCCCT ATCAGGTCTAAACCCAT

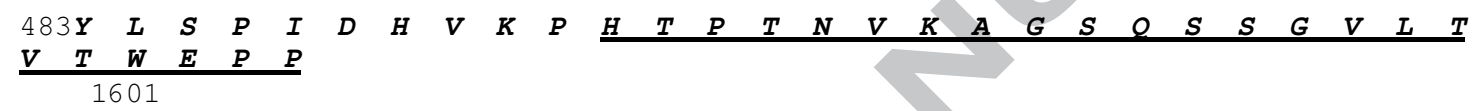
CTACCTGTCCCCCATAGATCACGTGAAACCCCACACACCCACTAACGTGAAGGCAGGGAGCCAGAGCAGCGGGGTCCTGACGG TCACATGGGAGCCGCCA

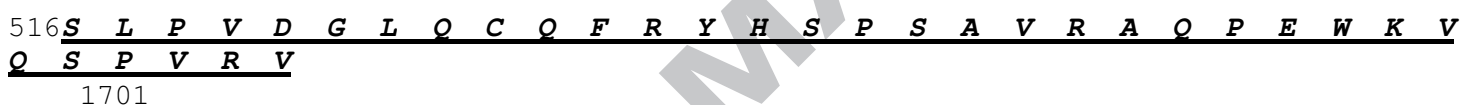
TCTCTGCCGGTCGACGGGCTTCAGTGTCAGTTTCGGTACCACTCACCATCCGCTGTGCGAGCCCAGCCGGAGTGGAAGGTCCA GAGTCCAGTGCGGGTGC

WSXWS-motif

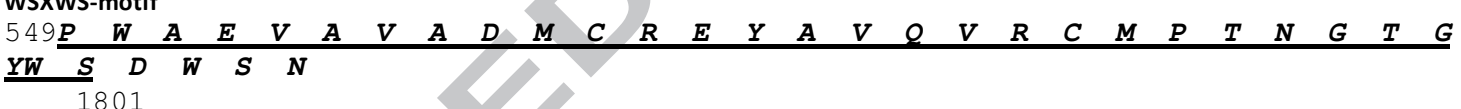
CGTGGGCGGAGGTCGCAGTGGCGGACATGTGCCGGGAGTATGCGGTGCAAGTACGCTGCATGCCCACTAATGGCACTGGCTAC TGGAGCGACTGGAGCAA

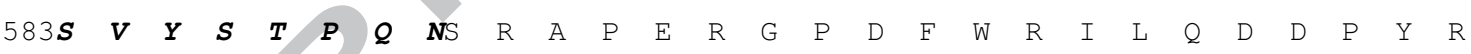
S $\quad 2 \quad \mathrm{~T} \quad \mathrm{~N} \quad \mathrm{~V}$ 1901

CTCGGTGTACTCCACACCTCAGAACAGCAGAGCTCCTGAGCGTGGCCCTGATTTCTGGAGAATCCTTCAGGATGATCCATACA GAAGCCAGACTAATGTC

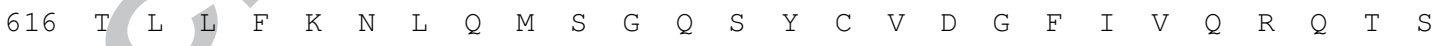
S G S V I R E 2001

ACTCTGCTGTTCAAGAATCTCCAAATGTCAGGGCAGTCTTACTGTGTGGATGGATTTATAGTCCAGCGCCAGACC TCGAGTGG CTCTGTGATAAGGGAGA

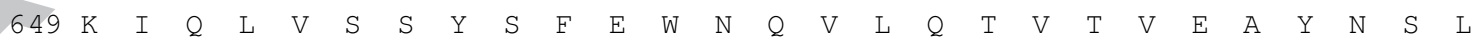
$\begin{array}{lllllllllll}G & S & S & A & N & N & I\end{array}$

2101

AGATCCAGCTGGTGTCTTCCTACAGCTTTGAGTGGAACCAGGTGCTCCAAACTGTGACTGTGGAGGCCTACAATAGTCTGGGG AGCTCCGCTAACAACAT

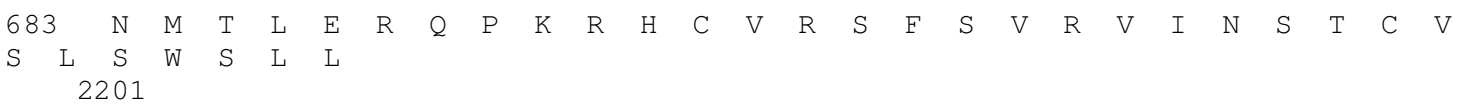
CAACATGACGCTGGAGAGACAGCCCAAACGCCACTGTGTGCGTTCATTCAGTGTGAGGGTTATCAACAGCACTTGTGTGTCTC TGTCCTGGAGTCTCTTG 


\section{ACCEPTED MANUSCRIPT}

$\begin{array}{llllllllllllllllllllllllllllllllll}716 & D & N & S & S & V & P & M & F & L & V & V & Q & W & S & P & Q & R & Q & P & D & S & G & Y & H & K & G\end{array}$

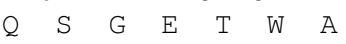
2301

GACAACAGCTCTGTACCCATGTTCCTGGTGGTCCAGTGGTCTCCACAGAGGCAACCGGACTCTGGTTATCACAAAGGCCAGAG TGGAGAAACATGGGCCA

$\begin{array}{lllllllllllllllllllllllllllllll}749 & R & L & P & Y & T & D & R & P & T & Y & L & R & G & D & F & F & G & S & E & E & C & G & F & S & L & Y & P\end{array}$ $\begin{array}{lllllllllllll} & \text { F } & A & D & G & E & G\end{array}$ 2401

GACTTCCCTACACTGACCGTCCCACATATCTAAGAGGTGATTTCTTTGGATCTGAGGAGTGTGGCTTCTCCCTGTACCCTGTG TTTGCAGATGGAGAAGG

TRANSMEMBRANE

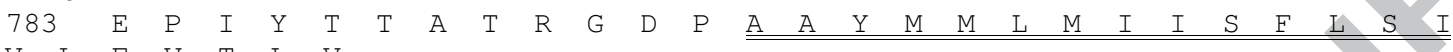

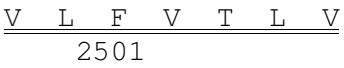

GGAGCCGATTTACACCACAGCCACTAGAGGAGACCCTGCAGCCTACATGATGCTGATGATCATCTCCTTCCTCTCCATCGTCC TGTTTGTCACCCTGGTC

JAK2 box1

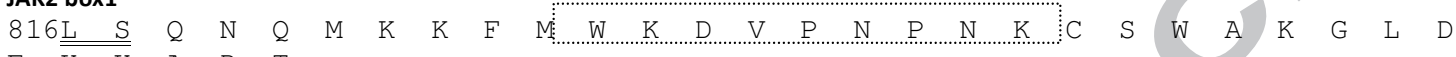

F $\underset{2601}{\mathrm{~K}} \underset{\mathrm{K}}{\mathrm{A}} \mathrm{A} \quad \mathrm{D} \quad \mathrm{T}$

CTCTCCCAAAACCAGATGAAAAAGTTTATGTGGAAGGATGTGCCCAACCCTAACAAGTGCTCCTGGGCCAAAGGACTAGACTT CAAAAAGGCTGACACCT

JAK2 box2

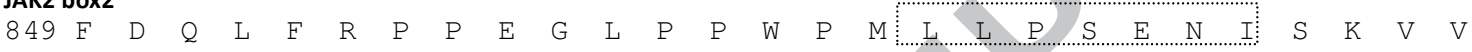

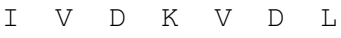
2701

TTGATCAGCTGTTCCGACCTCCAGAGGGCCTCCCACCCTGGCCGATGCTCCTTCCGTCGGAGAACATTTCCAAAGTCGTCATA GTGGACAAGGTTGATCT

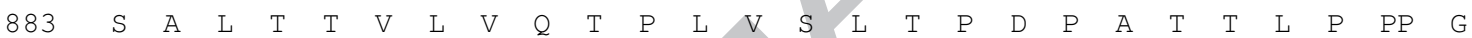
F $\quad D \quad S \quad E \quad V \quad$ D

2801

CTCAGCTCTGACTACGGTGTTAGTCCAAACCCCACTTGTGTCCCTAACTCCCGACCCAGCCACTACCTTGCCTCCTCCAGGGT TTGACTCAGAGGTTGAC

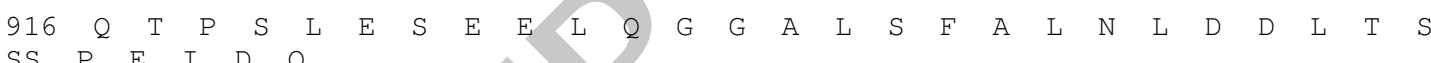

SS P E I D Q 2901

CAAACCCCATCCTTGGAGAGTGAGGAGCTCCAAGGTGGAGCTCTTTCCTTTGCACTTAATCTGGATGATTTAACCAGTTCAAG CCCAGAAATTGATCAGT

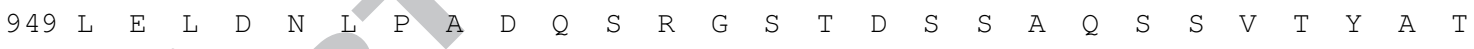
$\mathrm{V} \quad \mathrm{L} \quad \mathrm{L} \quad \mathrm{S} \quad \mathrm{D} \quad \mathrm{P} / \mathrm{K}$ 3001

TAGAGCTAGATAACCTCCCAGCAGACCAGTCCCGAGGCAGCACTGACAGCTCGGCCCAGTCTTCAGTCACGTACGCCACTGTC CTGCTCTCTGATCCGAA

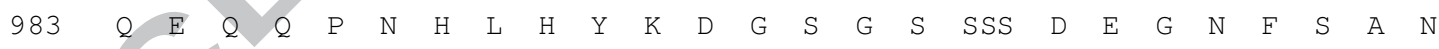
$\begin{array}{llllll}N & \mathrm{D} & \mathrm{I} & \mathrm{S} & \mathrm{G} \\ & & \end{array}$

GCAGGAGCAGCAGCCCAATCATCTCCACTACAAGGATGGTAGTGGCAGCAGCTCCAGCGATGAAGGCAATTTTTCTGCCAACA ACTCAGACATTTCTGGA

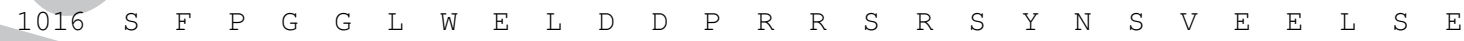
T S $\underset{3201}{ } \quad \mathrm{E} \quad \mathrm{G} \quad \mathrm{D} \quad \mathrm{E}$

TCTTTCCCCGGTGGCCTGTGGGAGCTGGATGACCCGCGGCGCTCCCGCTCCTACAACTCTGTGGAGGAGCTTTCTGAAACATC AGAGCAAGGAGACGAAG

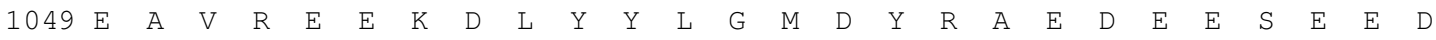
E E $\quad \mathrm{Q} \quad \mathrm{R} \quad \mathrm{E} \quad \mathrm{EE} \quad \mathrm{T}$ 3301

AAGCGGTGAGAGAGGAGAAGGACTTGTATTATTTAGGAATGGACTATCGTGCGGAGGATGAAGAGAGTGAGGAAGATGAGGAG CAGAGAGAAGAGGAGAC

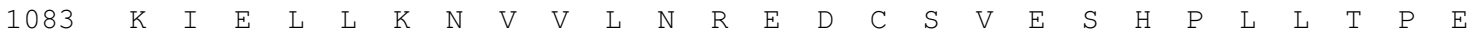
D $\quad S \quad S \quad E \quad L \quad L \quad S$ 
3401

AAAAATTGAGCTGCTTAAAAATGTGGTTTTGAACAGAGAGGACTGTTCTGTGGAGTCGCACCCTTTGCTCACACCTGAGGACT CCAGCGAGCTGCTGTCA

STAT box

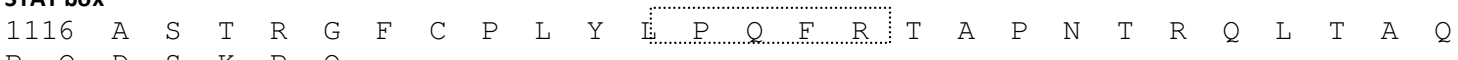
$\begin{array}{lllllll}P & Q & D & S & K & P & Q\end{array}$ 3501

GCATCGACACGTGGCTTT TGTCCGCTGTACCTGCCTCAGT TCAGAACTGCTCCCAACACAAGGCAACTCACAGCTCAACCACA AGACAGCAAACCCCAGG

$1149 \mathrm{~V} \&$

3601 TGTGA 
Fig. 2

HSa : ID-VNINISCETD--GYLTKMTCRWSTSTIQSLAESTLQLRYHRSSTY----CSDIPS IHP ISEPKDCYLQSDGF--

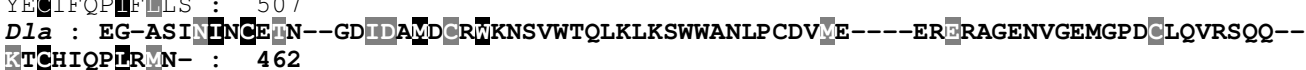

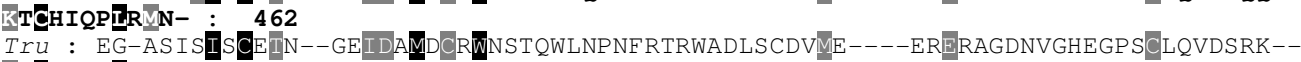
Tru : EG-ASIN
RLCITQPLRTN-: 464
ECO : QG-ASIDITCETN--GDIDAMTCSWKSTQWTRLKFRSRWADLQCDVME----ERERAGEKVGEMGP SCLLVRSKQ-ECO : QG-ASIDITCETN--GDIDAMTCSWKSTQWTRLKFRSRWADLQCDVME----ERERAGEKVGEMGP SCLQVRSKQ--
KTCTIQPLRMN- : 464 CCa : QGMFNADITCQSK-NSEEDTMRCEWNKSTWAQVRLLYSSRQHTMCETISEVEGSEEAEES-MSLVKECPSGAGDH--
RECTLRNLSLYS : 451 Ome : EG-ASLDIRCEIN--GDMDTMECSWNSTQWLSF NLQHKWT HMS CNSMK----QKEEAGENVGK IKEACF S IKP---RTCTFHPLHVG- : 471 Ola : EG-ASLDIRCETN--GNMDTMECSWNSTQWLSFNLQHKWTHMSCERMK----EKEEAGDNVGKIVDACYS I KP-----

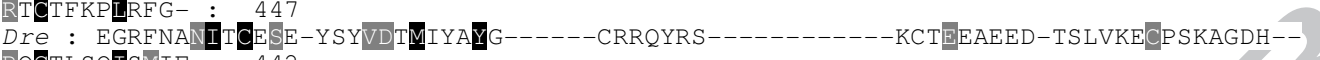
RQCTLSOISMIF : 442 SSa : KD-PVIDISCVTN--GDLDSMTCRWNNLPIGGINFMSRVADLSCDVME---EA ERVGVPVGVVRQAKCESSGYRGVKSCNLQPIRVTTS : 479 OmY : KD-PVIDISCVTS--GDLDSMTCR WNNLPIGGINFMSRVADLSCDVME----

EAERVGVPVGVVRQAKCESSGYRGVKSCNLQPIRVTS : 478

TfU: EGFFDAN TITEQHSSVDT TCK NKSAWAVIRF LYRRYRRTCDEIQYEEGT L TQAQGDPMVDVEECTAGAGDY--

YQCTLQDUSIS : 462

HSa :

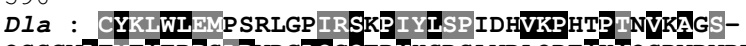

QSSGVZTVTTEEPES ITVDGLOCOFRYHSP SAVRAQPE EKKVOSPVRVPWA : 551

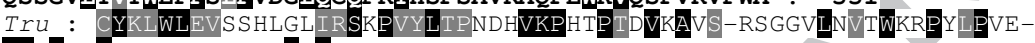

VQCDFRYHSPSADHPKPDWKVQAIVREPWA : 552

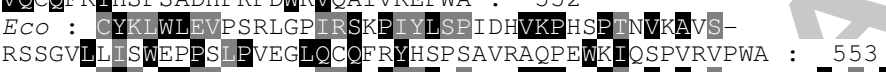

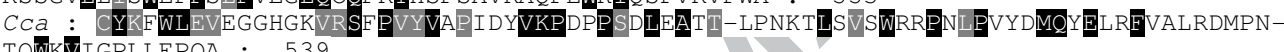

TQWKVI GPLLEPQA : 539 :

EDWKIQGTKQPPPM : 558

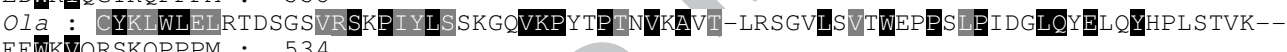

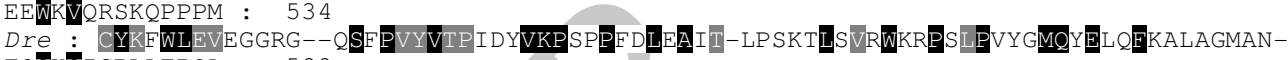

TQWKKI I I PLLEPQA : 528

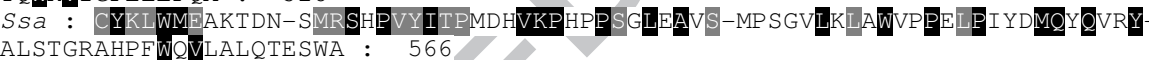

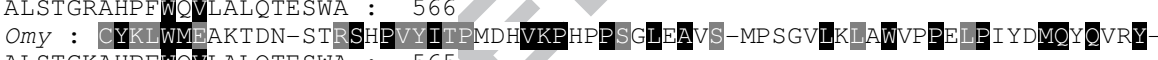

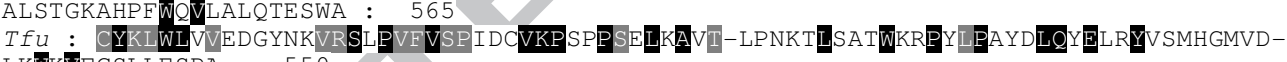

LK可KV̈FGSLLESRA : 550

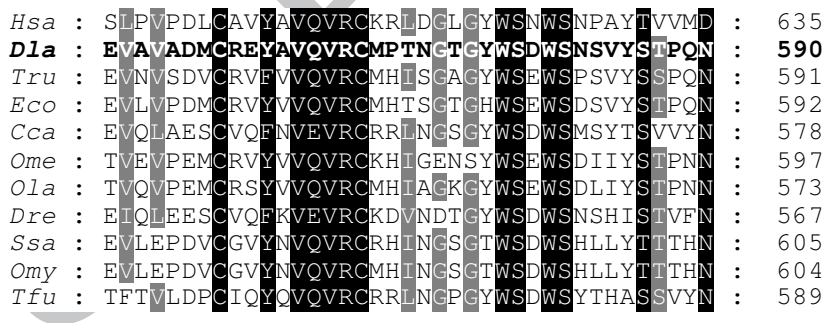


Fig. 3

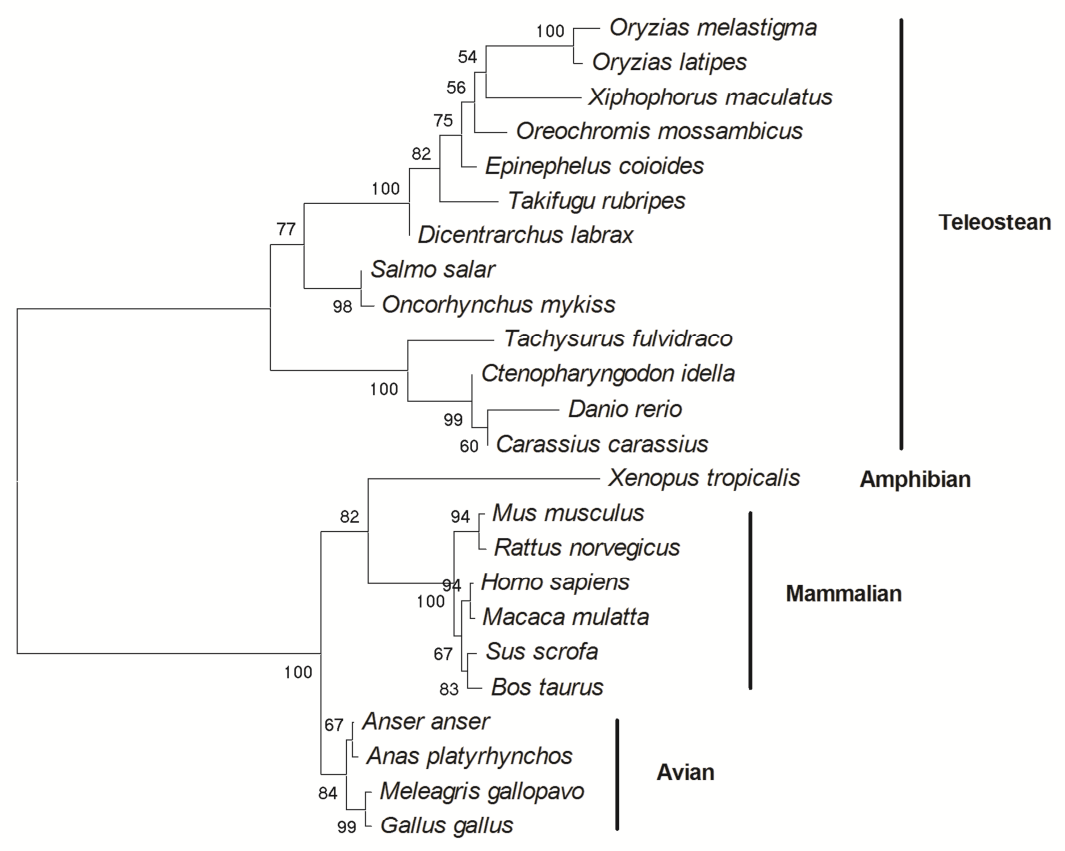


Fig. 4

Sea bass lepr exon $15^{\prime}-94 \mathrm{bp}$

1810

aggtcgcagtggcggacatgtgccgggagtatgcggtgcaagtacgctgcatgcccactaatggcactggctact ggagcgactggagcaactcggtgta

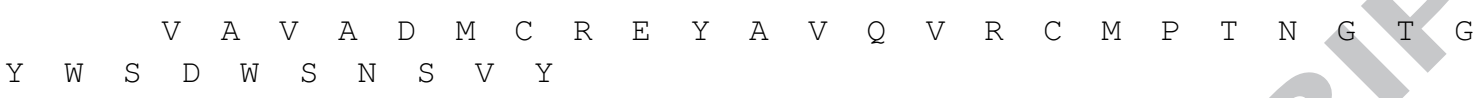
1910

ctccacacctcagaacagcagagccactagaggagaccctgcagcctacatgatgetgatgatcatctccttcct ctccatcgtcctgtttgtcaccctg

$\begin{array}{lllllllllllllllllllllllll}S & T & P & Q & N & S & R & A & T & R & G & D & P & A & A & Y & M & M & L & M & I & I & S\end{array}$ $\begin{array}{llllllllllllllllll} & \text { L } & \text { L } & \text { I } & \text { V } & \text { L } & \text { F } & \text { V } & \text { T } & \text { L }\end{array}$

2010 gtcctctcccaaaccagatgaaaaagtttatgtggaaggatgtgcccaaccctaacaagtgctcctgggc caaaggactagacttcaaaaggctgaca

$\begin{array}{lllllllllllllllllllllllllll} & & V & L & S & Q & N & Q & M & K & K & F & M & W & K & D & V & P & N & P & N & K & C & S & W\end{array}$

2110

cctttgatcagctgttccgacctccagagggcctcccaccctggccgatgctccttccgtcggagaacatttcca aagtcgtcatagtggacaaggttga

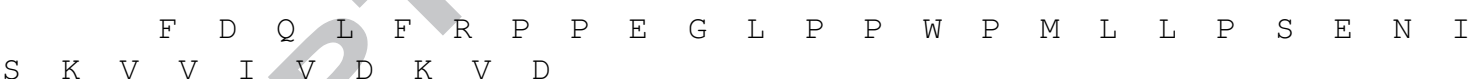

Sea bass lepr exon 15'-254bp

1810

aggtcgcagtggcggacatgtgccgggagtatgcggtgcaagtacgctgcatgcccactaatggcactggctact ggagcgactggagcaactcggtgta

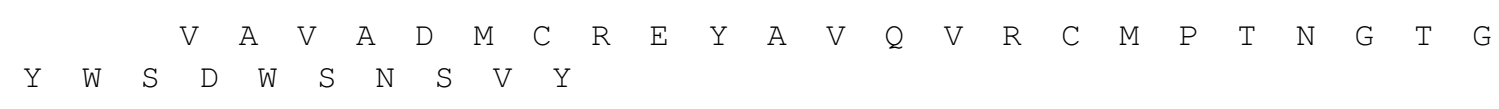

1910

ctccacacctcagaacagcagaggtacaatggagaaggggagccgatttacaccacaggtatgctccagttgcgt gaatgttatatcagttccatattca 


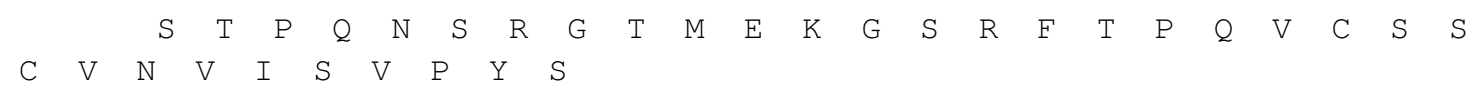

2010

ccattgaagtgtttaagggtgacacagtgccagtactttaattgtgttattaattataggtctgatgtgtatttt ccaactgttacagccactagaggag

$\begin{array}{llllllllllllllllllllllllll} & & \mathrm{P} & \mathrm{L} & \mathrm{K} & \mathrm{C} & \mathrm{L} & \mathrm{R} & \mathrm{V} & \mathrm{T} & \mathrm{Q} & \mathrm{C} & \mathrm{Q} & \mathrm{Y} & \mathrm{F} & \mathrm{N} & \mathrm{C} & \mathrm{V} & \mathrm{I} & \mathrm{N} & \mathrm{Y} & \mathrm{R} & \mathrm{S} & \mathrm{D} & \mathrm{V}\end{array}$

2110

accetgcagcctacatgatgctgatgatcatctccttcctctccatcgtcctgtttgtcaccctggtcctctccc aaaccagatgaaaagtttatgtg

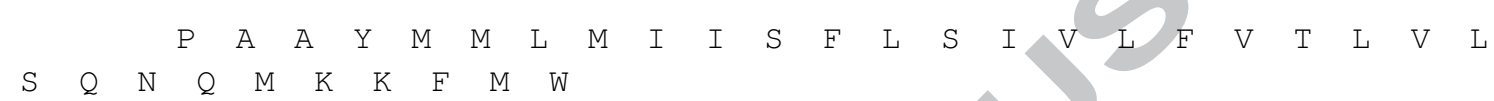
2210

gaaggatgtgcccaaccctaacaagtgctcctgggccaaaggactagacttcaaaaggctgacacctttgatca gctgttccgacctccagagggcctc

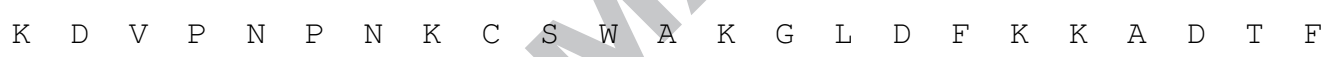
$\begin{array}{llllllllllllllll}D & Q & L & F & R & P & P & E & G & L\end{array}$ 
Fig. 5

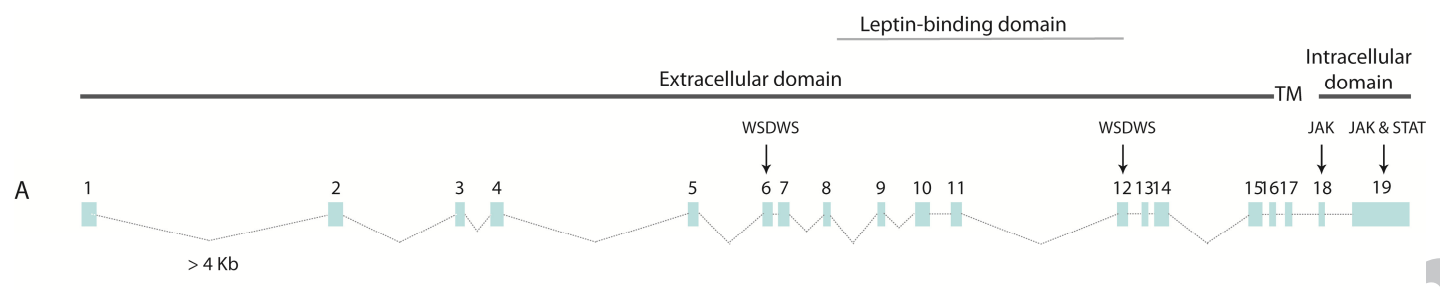

$\begin{array}{llllllllllllll}1 & 2 & 3 & 4 & 5 & 67 & 8 & 9 & 10 & 11 & 121314 & 15^{\prime} & 18 & 19\end{array}$
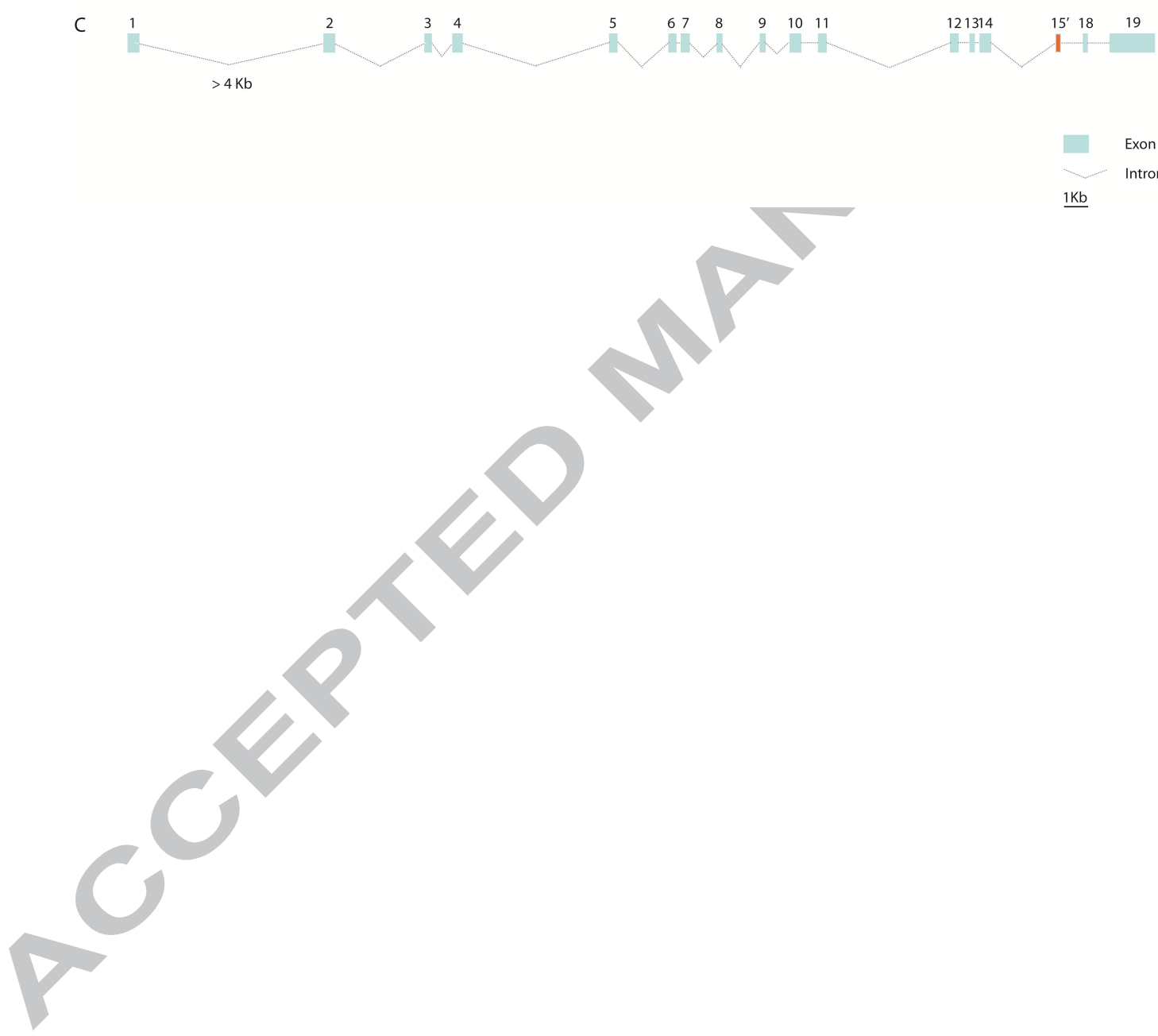

Exon
$1 \mathrm{~Kb}$


Fig. 6

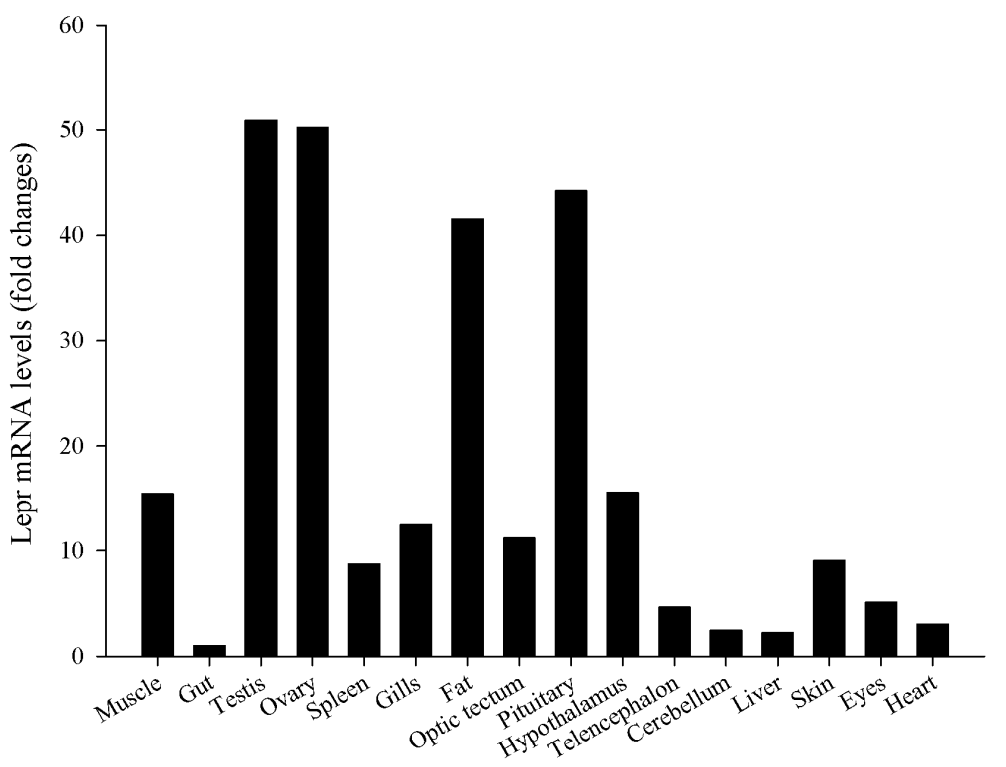

Tissues 
Fig. 7
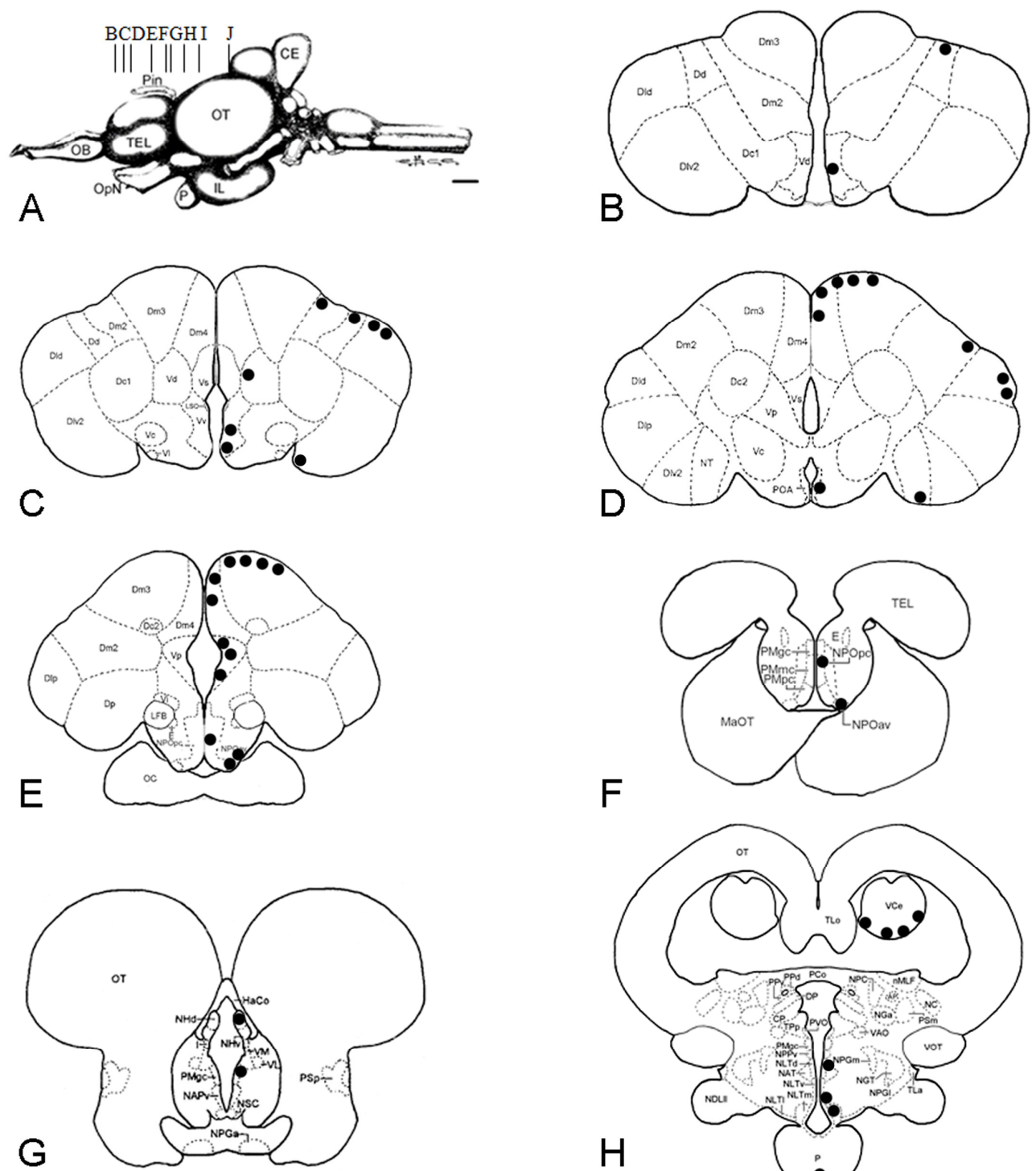

F
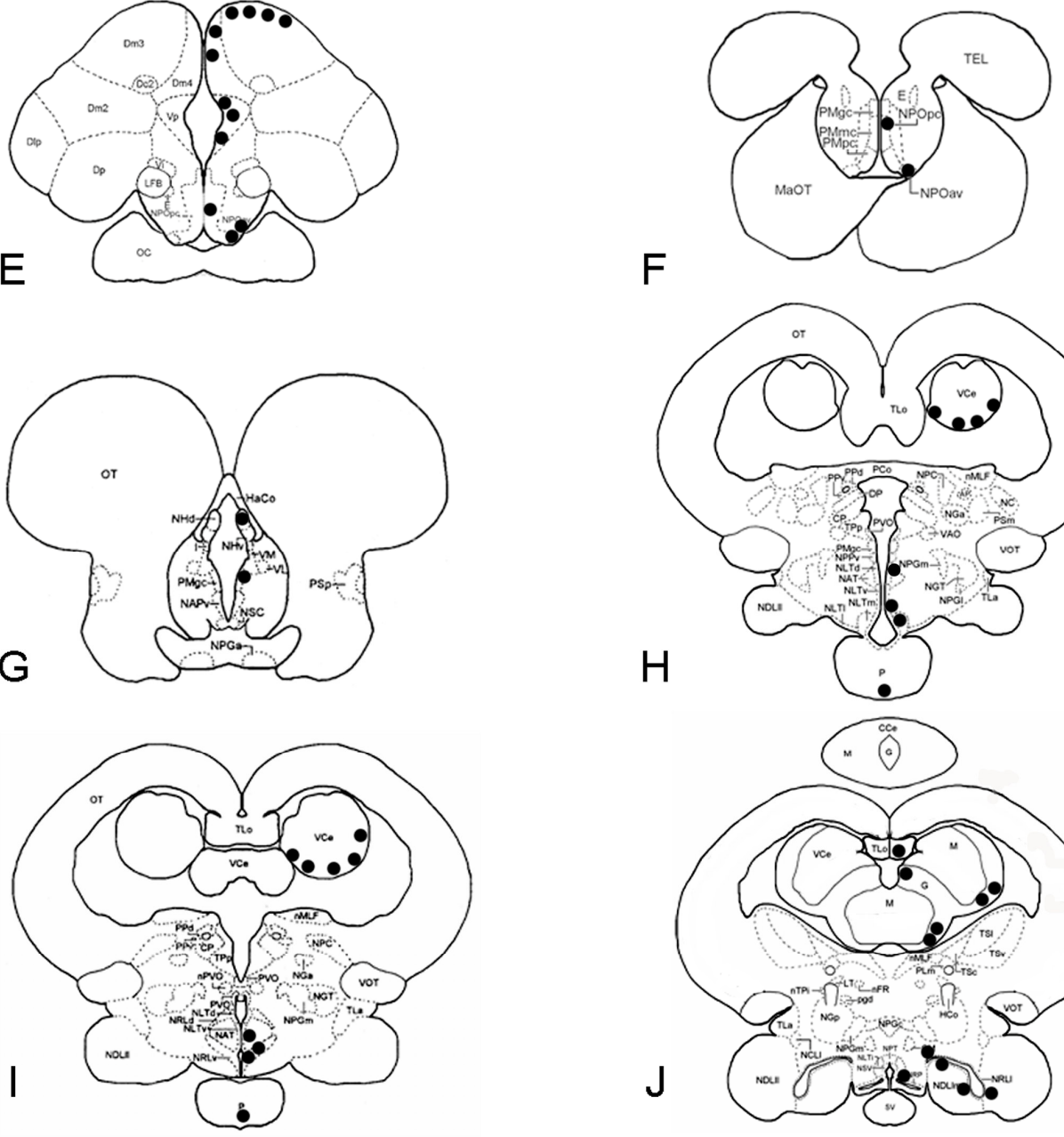

$\mathrm{H}$
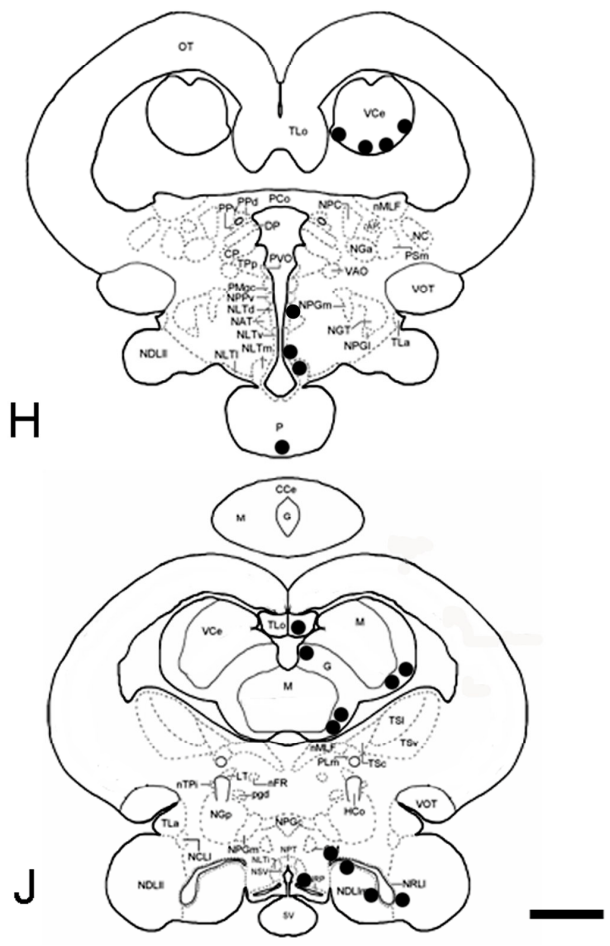
Fig. 8
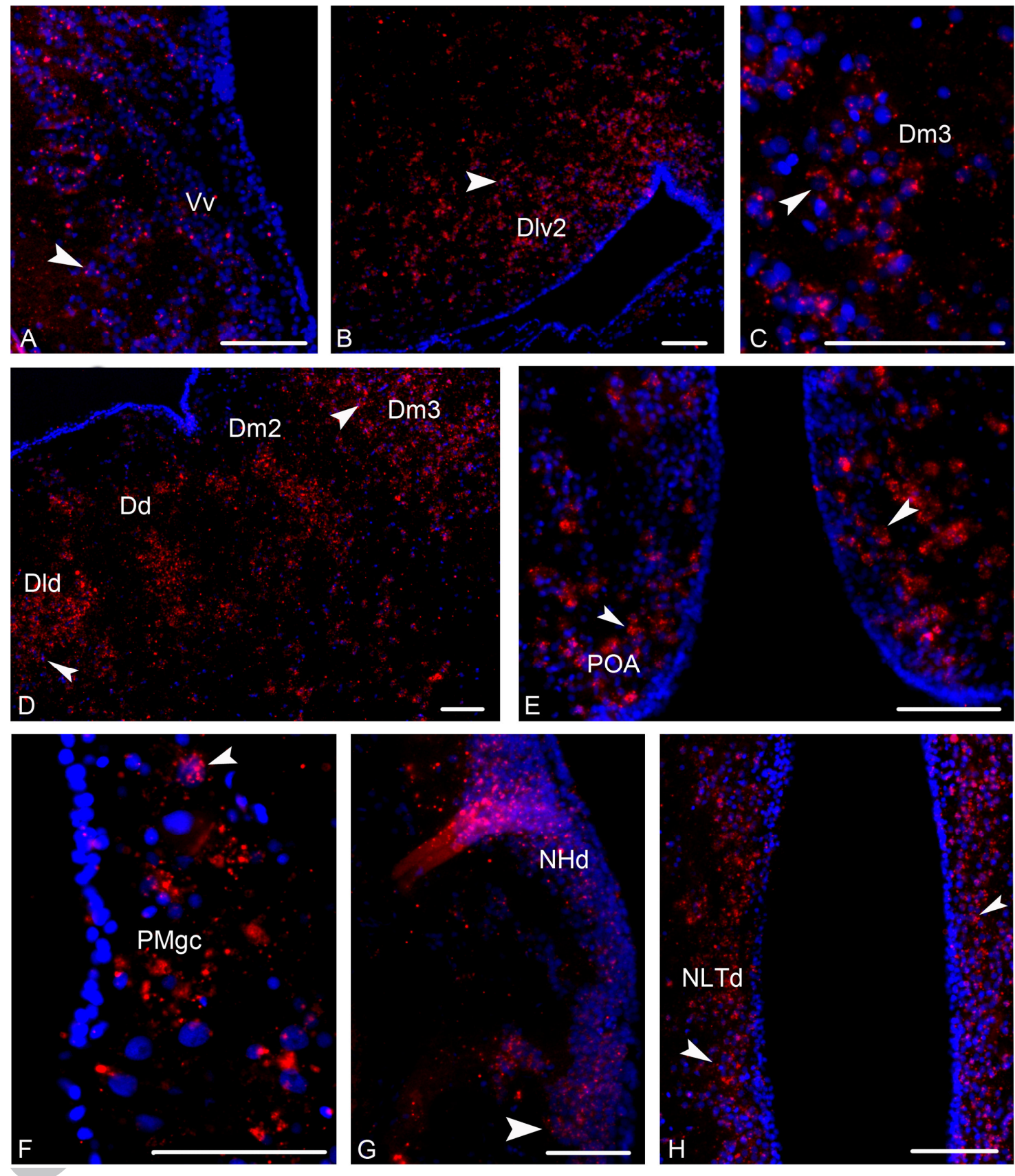


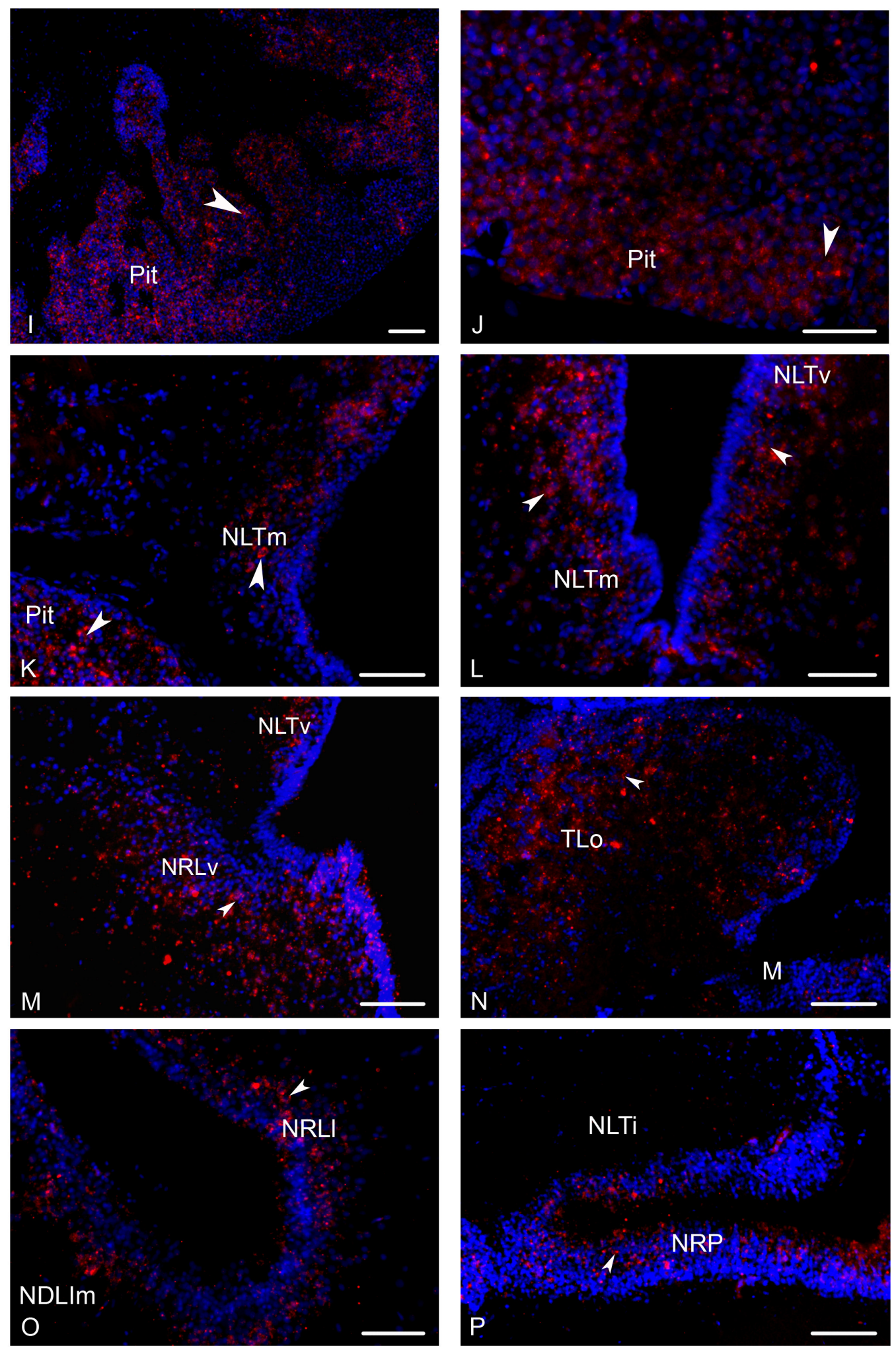




\section{Highlights}

- Sblepr is a single copy gene and widely distributed in tissues involved in metabolism and reproduction

- Two alternative splicing variants miss their transmembrane domain but conserve JAK/STAT signalling capability

- sblepris highly expressed in brain areas previously related with metabolism and reproduction 